\title{
Global sensitivities of forest carbon changes to environmental conditions
}

\author{
Simon Besnard ${ }^{1,2} \odot$ | Maurizio Santoro ${ }^{3}$ | Oliver Cartus ${ }^{3}$ | Naixin Fan ${ }^{1}$ | \\ Nora Linscheid $^{1}$ | Richard Nair ${ }^{1}$ (0) Ulrich Weber ${ }^{1}$ | Sujan Koirala ${ }^{1}$ | Nuno Carvalhais ${ }^{1,4}$
}

\author{
${ }^{1}$ Max Planck Institute for Biogeochemistry, \\ Jena, Germany \\ ${ }^{2}$ Laboratory of Geo-Information Science \\ and Remote Sensing, Wageningen \\ University \& Research, Wageningen, The \\ Netherlands \\ ${ }^{3}$ Gamma Remote Sensing, Gümligen, \\ Switzerland \\ ${ }^{4}$ Departamento de Ciências e Engenharia \\ do Ambiente, DCEA, Faculdade de \\ Ciências e Tecnologia, FCT, Universidade \\ Nova de Lisboa, Caparica, Portugal

\section{Correspondence} \\ Simon Besnard and Nuno Carvalhais, Max \\ Planck Institute for Biogeochemistry, \\ Hans-Knöll-Strasse 10, 07745 Jena, \\ Germany. \\ Emails: sbesnard@bgc-jena.mpg.de (S. B.) \\ and ncarvalhais@bgc-jena.mpg.de (N. C.)
}

\begin{abstract}
The responses of forest carbon dynamics to fluctuations in environmental conditions at a global scale remain elusive. Despite the understanding that favourable environmental conditions promote forest growth, these responses have been challenging to observe across different ecosystems and climate gradients. Based on a global annual time series of aboveground biomass (AGB) estimated from radar satellites between 1992 and 2018, we present forest carbon changes and provide insights on their sensitivities to environmental conditions across scales. Our findings indicate differences in forest carbon changes across AGB classes, with regions with carbon stocks of $50-125 \mathrm{MgC} \mathrm{ha}^{-1}$ depict the highest forest carbon gains and losses, while regions with 125-150 MgC ha-1 have the lowest forest carbon gains and losses in absolute terms. Net forest carbon change estimates show that the arc-of-deforestation and the Congo Basin were the main hotspots of forest carbon loss, while a substantial part of European forest gained carbon during the last three decades. Furthermore, we observe that changes in forest carbon stocks were systematically positively correlated with changes in forest cover fraction. At the same time, it was not necessarily the case with other environmental variables, such as air temperature and water availability at the bivariate level. We also used a model attribution method to demonstrate that atmospheric conditions were the dominant control of forest carbon changes $56 \%$ of the total study area) followed by water-related ( $29 \%$ of the total study area) and vegetation (15\% of the total study area) conditions. Regionally, we find evidence that carbon gains from long-term forest growth covary with long-term carbon sinks inferred from atmospheric inversions. Our results describe the contributions from the atmosphere, water-related and vegetation conditions to forest carbon changes and provide new insights into the underlying mechanisms of the coupling between forest growth and the global carbon cycle.
\end{abstract}

\section{KEYWORDS}

atmosphere, carbon changes, carbon cycle, C-band aboveground biomass, global forests, vegetation, water 


\section{1 | INTRODUCTION}

Terrestrial carbon uptake from the atmosphere via photosynthesis is the most significant carbon dioxide $\left(\mathrm{CO}_{2}\right)$ flux (Beer et al., 2010), while at least half of the land-to-atmosphere fluxes via autotrophic respiration occurred in terrestrial ecosystems (Collalti \& Prentice, 2019). Roughly half of these fluxes occurred in forested ecosystems (Beer et al., 2010) that store around $80 \%$ of all the biomass on Earth (Bar-On \& Milo, 2019) and sequestered around $3.5 \pm 1.0 \mathrm{PgC} \mathrm{yr}^{-1}$ during the last decade (Le Quéré et al., 2018). However, diagnosing the temporal dynamics from annual to a decadal scale of forest carbon changes has posed a substantial challenge until now. The limited information on forest carbon changes in time hinders understanding the natural processes that govern the terrestrial carbon cycle's contemporary dynamics and has direct implications in prognostic modelling uncertainties (Friedlingstein et al., 2013).

Functionally, temporal and spatial changes in forest biomass emerge from the net integral of carbon gains and losses, which have an essential role in the global carbon budget (Mitchard, 2018). On the one hand, carbon is assimilated via photosynthesis (gross primary production, GPP). The assimilated carbon is further used to produce organic matter (net primary production, NPP) and allocated to above- and below-ground compartments, representing the main processes that control gross biomass production over time. On the other hand, carbon stored in forests can also be released due to plant metabolism (autotrophic respiration, Ra), litterfall and plant mortality (Thurner et al., 2016), as well as episodic natural/anthropogenic disturbance events (Liu et al., 2011).

Forest characteristics such as forest age and species composition play a crucial role in forest growth (Besnard et al., 2018; Carvalhais et al., 2010; Odum, 1969). Yet, the structure of a forest can be negatively impacted by climate extremes and associated disturbance regimes (Frank et al., 2015). For instance, changes in leaf area during extreme conditions can affect tree growth and consequently modulate the atmospheric carbon dioxide $\left(\mathrm{CO}_{2}\right)$ growth rate (Bastos et al. 2019). A recent study shows that biomass production increases with higher atmospheric water demand in the humid Amazon regions (Green et al., 2020), although areas of tropical forests exposed to dry and hot conditions during 2015-2016 El Niño episodes showed a decrease in net primary productivity and an increase in mortality (Brienen et al., 2015; Phillips et al., 2009; Saatchi et al., 2013; Verbesselt et al., 2016). The increased number and intensity of extreme events such as droughts and heatwaves is expected to have adverse effects on the forest carbon stocks (Reichstein et al., 2013). Changes in nitrogen deposition (Ndep) is an essential driver in modulating forest growth in temperate Europe (Etzold et al., 2020), while different effects of Ndep on forest growth have been observed (Engardt et al., 2017; Vuorenmaa et al., 2018; Waldner et al., 2014). Increased Ndep can stimulate forest growth in $\mathrm{N}$-limited forests, while high Ndep on non-N-limited regions can potentially reduce forest growth (de Vries et al., 2014; Gessler et al., 2017). Aside from environmental conditions, anthropogenic activities, such as the increase in harvested forest area and deforestation rate (Achard et al.,
2014; Hansen et al., 2013; Miettinen et al., 2011), impact changes in forest carbon stocks.

Due to the central role of forest ecosystems in Earth system dynamics (Bonan, 2008), it is essential to accurately monitor forest biomass's spatial and temporal characteristics for modelling carbonclimate interactions. However, there is not enough context to mechanistically understand changes in forest carbon stocks globally from annual to decadal timescales across different ecosystems and climates. Forest biomass dynamics are usually estimated from measurements collected during surveys of forest inventories, but these estimates are usually sparse in space and time. The limited information on temporal changes in global below- and aboveground biomass (AGB) impedes our current ability to quantify the mechanisms that control the temporal dynamics of forest AGB (Baccini et al., 2017; Reichstein \& Carvalhais, 2019).

Remote sensing observations can support the understanding of biomass dynamics. Nevertheless, remote sensing does not provide a quantitative measure of the organic mass stored in vegetation; thus any application that aims at inverting satellite observations to mass requires a modelling framework, which implies that the AGB estimates are affected by uncertainties. One of the longest records of observations from space consists of the C-band (wavelength of $6 \mathrm{~cm}$ ) backscattered intensity received by space-borne scatterometers. Scatterometers are active sensors that operate regardless of solar illumination and cloud cover. C-band backscatter measurements were used for monitoring AGB (Santoro et al., 2021). Recently, multiple C-band sensors were merged to capture multi-decadal information on the signature of the aboveground vegetation both in space and time (Santoro et al., 2020).

Here, we use a novel global dataset of AGB estimates derived from scatterometer observations spanning almost three decades (1992-2018) to explore the responses of forest carbon stocks to fluctuations in environmental conditions. Specifically, we use the longterm global AGB dataset to (1) provide estimates of global changes in forest carbon stocks over time and (2) investigate the controls of atmosphere, water-related and vegetation conditions on the changes in forest carbon stocks from local to global scales. Ultimately, we (3) explore the link between long-term changes in forest carbon stocks and the net ecosystem carbon fluxes at a regional scale.

\section{2 | MATERIALS AND METHODS}

\subsection{Retrieving aboveground biomass from C-band scatterometer}

The dataset of annual AGB estimates was obtained from observations of the backscattered intensity collected by satellite scatterometers operating at the C-band between 1992 and 2018. An almost unbroken time series of up to daily observations by the European Remote Sensing (ERS) WindScatterometer and the MetOp Advanced SCATterometer (ASCAT) was used in an AGB retrieval approach that maximizes the information content on forest 
structural parameters in the data while reducing external contributions to the backscatter due to moisture conditions, precipitation and snow cover. For each year, all daily observations of the radar backscatter at one location (pixel size of $0.25^{\circ}$ ) were synthesized to generate a single estimate of AGB, allowing for a smooth time series of AGB estimates (Santoro et al., 2020). The uncertainties of the annual AGB estimates consisted of a variance term expressed as the weighted average of the individual, daily uncertainties of AGB and a covariance term. The covariance terms took into account the temporal correlation between the individual $A G B$ estimates and their errors. The assessment of the $A G B$ estimates for the year 2010 was strongly correlated with spaceborne LiDARbased metrics of vegetation structure (canopy density and height) and with AGB averages from forest field inventory plots collected around the same epoch (Santoro et al., 2020). For this study, the AGB estimates, expressed as dry organic mass, were converted to carbon density using the Intergovernmental Panel on Climate Change (IPCC) default carbon fraction of 0.47 (McGroddy et al., 2004). Carbon stock estimates were considered to be directly compared with net land-atmosphere surface fluxes (see Section 2.5).

We explored the spatio-temporal dynamics in forest carbon gain/loss (i.e. dAGB/dt, hereafter net aboveground biomass production (NABP)). The metric NABP for AGB estimate can be expressed as:

$$
\mathrm{NABP}=\mathrm{AGB}_{\mathrm{t}}-\mathrm{AGB}_{\mathrm{t}-1}
$$

where $A G B_{t}$ is the $A G B$ estimate at a time step $t$ and $A G B_{t-1}$ is the $A G B$ estimate at a time step $\mathrm{t}-1$ for a specific pixel.

The uncertainty of NABP $(\sigma)$ for each estimate can be expressed as:

$$
\sigma \mathrm{NABP}=\sqrt{\sigma \mathrm{AGB}_{\mathrm{t}}^{2}+\sigma \mathrm{AGB}_{\mathrm{t}-1}^{2}}
$$

where $\sigma A G B_{t}$ is the AGB uncertainty estimate at a time step $t$ and $\sigma A G B_{t-1}$ is the $A G B$ uncertainty estimate at a time step $t-1$ for a specific pixel.

The aggregated uncertainty of $\operatorname{NABP}(\sigma)$ for a pixel can be expressed as:

$$
\sigma \mathrm{NABP}=\frac{1}{n} \sqrt{\sum_{\mathrm{t}=1}^{n} \sigma \mathrm{NABP}_{\mathrm{t}}^{2}}
$$

where $\sigma \mathrm{NABP}_{\mathrm{t}}$ is the NABP uncertainty estimate at a time step t for a specific pixel (Equation 2) and $n$ is the number annual estimates for each pixel.

\section{2 | Datasets and data pre-processing}

To provide a global data-driven perspective on the controls of environmental conditions on NABP, we considered a set of global datasets listed in the following sections. All the post-processing steps performed on the data are also described.

\subsection{1 | Variables for atmosphere conditions}

To characterize the atmosphere conditions, we first collected a series of climatic variables from the ERA5-reanalysis data. Daily air temperature at 2-m height (temperature) and surface solar radiation downwards (solar radiation) at a $0.25^{\circ}$ pixel size for the period of 1992 to 2018 (https://apps.ecmwf.int/datasets/licences/copernicus/) were used. Additionally, we used daily air temperature, specific humidity and air pressure products at $0.25^{\circ}$ pixel size from the ERA5-reanalysis data for 1992 to 2018 to calculate daily vapour pressure deficit (VPD), representing the demand of the water in the atmosphere, according to the first principles of Monteith and Unsworth (2007). Daily temperature, solar radiation and VPD estimates were further averaged at the annual scale. Additionally, we computed lagged variables (i.e. 2year lagged estimates; *-lag2 variables) for each atmosphere variable as proxies for recent-past atmosphere conditions.

Furthermore, we used the gridded annual estimates of Ndep and phosphorus deposition (Pdep) at a $0.5^{\circ}$ pixel size calculated in the LMDZ-INCA global aerosol chemistry-climate model prescribed by reconstructions of historical and future scenarios of anthropogenic emissions (Wang et al., 2017). The LMDZ-INCA couples the LMDz (Laboratoire de Météorologie Dynamique, version-4) General Circulation Model (Hourdin et al., 2006) and the INCA (INteraction with Chemistry and Aerosols, version-4) aerosol module (Hauglustaine et al., 2014). The Ndep and Pdep products were resampled to a $0.25^{\circ}$ pixel size to match the pixel size of the $A G B$ products using bilinear interpolation, and we used Ndep, and Pdep estimates spanning the period 1992-2018.

\subsubsection{Water-related variables}

The water-related variables were total precipitation (precipitation) and the volumetric soil water layer $1(0-7 \mathrm{~cm})$ (SM layer 1), 2 (7$28 \mathrm{~cm}$ ) (SM layer 2), $3(28-100 \mathrm{~cm})$ (SM layer 3) and $4(100-289 \mathrm{~cm})$ (SM layer 4) from the ERA5-reanalysis data at a $0.25^{\circ}$ pixel size. Daily precipitation estimates were summed at the annual scale, while daily estimates of each SM layer were averaged at the annual scale. In addition to the precipitation and SM layers, we used an index of water availability (IWA) (Tramontana et al., 2016) to further characterize soil water availability for the plants. IWA estimates were computed as follows:

$$
\mathrm{IWA}=\frac{\text { Evaporation }}{\text { Evaporation }_{\text {potential }}}
$$

Evaporation $_{\text {potential }}\left(\mathrm{E}_{\mathrm{pot}}\right)$ was calculated based on Priestley-Taylor equation (Priestley \& Taylor, 1972) and scaled with the fraction of photosynthetic active radiation (fPAR), which was based on mean seasonal cycle of Moderate Resolution Imaging Spectroradiometer (MODIS) data (Tramontana et al., 2016).

$$
E_{\text {pot }}=f P A R \times E_{P T}
$$


Evapotranspiration $(E)$ was taken as the minimum of demand $\left(E_{\text {pot }}\right)$ and water supply $\left(E_{\text {supply }}\right)$ driven $E$, where $E_{\text {supply }}$ was modelled as a fraction ( $k$ ) of soil water storage (SWS) (Teuling et al., 2006):

$$
E_{\text {supply }}=k \times\left(\mathrm{SWS}_{\mathrm{t}-1}+\text { Recharge }\right)
$$

We also retrieved the precipitation and soil water availability estimates 2 years before (i.e. *-lag2 variables) as proxies for recent-past water-related conditions.

\subsection{3 | Variables for vegetation conditions}

The Land Cover CCl (CCl-LC) product (https://www.esa-landcovercci.org/?q=node/164) was used to estimate the temporal changes in forest fractions from 1992 to 2018 . The CCI-LC dataset consists of yearly, global estimates of land cover with a pixel size of $300 \mathrm{~m}$. First, for each year and each $0.25^{\circ}$ pixel, the fraction of each of the 22 land cover classes was computed. We then summed the fractions of those classes associated with forest ecosystems ${ }^{1}$ within each $0.25^{\circ}$ pixel. We estimated the total forest cover fraction for each year at $0.25^{\circ}$ from 1992 to 2018 . From these annual forest fraction estimates, changes in forest fraction (hereafter $\Delta$ forest fraction) were calculated as follows:

$$
\Delta \text { forestfraction }=\text { forestfraction }_{\mathrm{t}}-\text { forestfraction }_{\mathrm{t}-1}
$$

We also derived a forest mask from the annual forest fraction estimates by computing the quantile $5 \%$ of the forest cover fraction for the period 1992-2018 and retaining the pixels with quantile estimates above $20 \%$ of forest fraction.

The Global Land Surface Satellite (GLASS) LAI data (Xiao et al., 2016) provided monthly estimates of plant canopy characteristics from 1992 to 2018 with a $0.25^{\circ}$ pixel size. Before aggregating LAI estimates from a monthly to annual scale, we masked out observations that were both below the $5 \%$ quantile of the monthly LAI estimates and a temperature of $5^{\circ} \mathrm{C}$ or below the $5 \%$ quantile of the monthly LAI estimates and total monthly precipitation of $30 \mathrm{~mm} \mathrm{month}^{-1}$ within each year in order to filter out LAI observations for which we assumed the plants to be photosynthetically inactive (Figure S14-S16). These filtered LAI monthly estimates were averaged to an annual scale. Additionally, the changes in LAI between a year and the previous year (hereafter $\Delta \mathrm{LAl}$ ) were computed as follows:

$$
\Delta \mathrm{LAI}=\mathrm{LAI}_{\mathrm{t}}-\mathrm{LAI}_{\mathrm{t}-1}
$$

\footnotetext{
${ }^{1}$ Tree or shrub cover, Mosaic natural vegetation (Tree, shrub, herbaceous cover) (>50\%)/ cropland $(<50 \%)$, Tree cover, broadleaved, evergreen, closed to open $(>15 \%)$, Tree cover, broadleaved, deciduous, closed to open $(>15 \%)$, Tree cover, broadleaved, deciduous, closed (>40\%), Tree cover, broadleaved, deciduous, open (15\%-40\%), Tree cover, needleleaved, evergreen, closed to open $(>15 \%)$, Tree cover, needleleaved, evergreen, closed (>40\%), Tree cover, needleleaved, evergreen, open (15\%-40\%), Tree cover, needleleaved, deciduous, closed to open ( $>15 \%)$, Tree cover, needleleaved, deciduous, closed (>40\%), Tree cover, needleleaved, deciduous, open (15\%-40\%), and Tree cover, mixed leaf type (broadleaved and needleleaved).
}

Median ensembles of both GPP and ecosystem respiration (Reco) FLUXCOM-RS+METEO products (Jung et al., 2011, 2020; Tramontana et al., 2016) from 1992 to 2018 at a $0.5^{\circ}$ pixel size were calculated as proxies for ecosystem photosynthesis and respiration processes respectively. We also created a median ensemble of the GPP FLUXCOM-RS products (Jung et al., 2011, 2020; Tramontana et al., 2016) from 2001 to 2018 at a $0.5^{\circ}$ pixel size. The FLUXCOMRS+METEO products used meteorological data and mean seasonal cycles of MODIS satellite data, while the FLUXCOM-RS products contained information on changes in vegetation state from MODIS satellite data exclusively. Both GPP and RECO products were averaged from monthly to annual scale after filtering out monthly observations similarly to LAl time series. Annual GPP and RECO estimates were further resampled to $0.25^{\circ}$ pixel size to match the pixel size of the AGB products using bilinear interpolation.

We computed 2-year lagged AGB estimates (hereafter $\mathrm{AGB}_{\operatorname{lag} 2}$ ) to retrieve information on the recent-past carbon stocks. Two-year lagged estimates were chosen instead of 1-year lagged estimates to avoid a potential spurious relationship between NABP estimates and the lagged $A G B$ estimates. $A_{G B} B_{\operatorname{lag} 2}$ was computed as follows:

$$
\mathrm{AGB}_{\text {lag2 }}=\mathrm{AGB}_{\mathrm{t}-2}
$$

\subsubsection{Atmospheric data and inversions}

We used the Jena CarboScope inversion versions s93oc-v2020 dataset of net land-atmosphere surface fluxes from 1992 to 2018 at $1^{\circ}$ pixel size (Rödenbeck et al., 2018) to compute the land sink from model inversion. This atmospheric inversion product provided estimates of Net Biome productivity (NBP), which was characterized as the integral of the photosynthesis, respiration and disturbance fluxes. Atmospheric inversion-based NBP estimates were aggregated at the regional scale over the 14 Global Fire Emissions Database (GFED) regions (Giglio et al., 2013) (Figure S17) because atmospheric inversions are better constrained over large spatial scales.

\section{3 | Comparing forest carbon changes with environmental conditions}

Annual NABP estimates were partitioned between years with carbon gains (i.e. $N A B P>0$ ) and years with carbon losses (i.e. NABP $<0$ ). Both annual carbon gains and losses were mapped globally and presented independently across different $A G B$ intervals (i.e. 1-25, 25-50, 50-75, 75-100, 100-125, 125-150 and 150-250 MgC ha-1). Additionally, net carbon loss and gains for the period 1992-2018 were computed as the mean NABP estimates at the pixel level and mapped globally.

Furthermore, we compared the bivariate relationship between NABP with the aforementioned independent datasets (see Section 2.2). For each variable, the global signals represent an area-weighted global average of each year. Finally, we performed a correlation 
FIGURE 1 Global distribution of the different $25 \times 25$ spatial window (a) and spatio-temporal cross-validation scheme within each $25 \times 25$ spatial window (b)

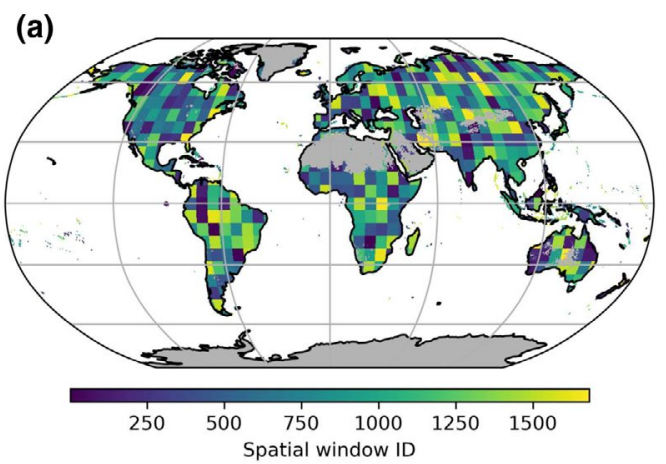

(b)

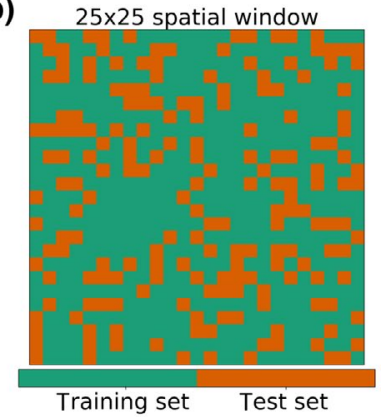

TABLE 1 List of the variables included in each group

\begin{tabular}{|c|c|c|c|}
\hline & Vegetation & Water related & Atmosphere \\
\hline
\end{tabular}

Abbreviations: AGB, aboveground biomass; GPP, gross primary productivity; IWA, index of water availability; LAI, leaf area index; N, nitrogen; P, phosphorus; RECO, ecosystem respiration; SM, soil moisture; VPD, vapour pressure deficit.

analysis comparing NABP against each of the datasets above at pixel level using Spearman's rank correlation coefficient.

\section{4 | Relative importance of atmosphere, water- related and vegetation conditions}

We further examined the relative importance of environmental conditions in determining the spatio-temporal patterns of NABP from local to global scales based on Gradient Boosting algorithms (https://xgboost.readthedocs.io) (XGBoost) trained within $25 \times 25$ pixel spatial windows (Figure 1a). The choice of spatial window size of $25 \times 25$ pixels during the training procedure was justified to limit confounding effects related to the spatial variability in the input variables. An XGBoost model is a boosting algorithm that builds an ensemble of shallow decision trees sequentially where subsequent models correct the performance of prior models. We standardized the NABP estimates for each pixel independently to focus on the temporal variations in NABP. We created three groups of variables that translated concurrent or lagged vegetation, atmosphere and water-related conditions (Table 1).

To remove potential collinearity between the atmosphere, water-related and vegetation variables (Table 1), we first performed a principal component analysis (PCA) for each group of variables independently within $25 \times 25$ pixel spatial windows. We kept the first five axes of each PCA (i.e. variance explained $>0.8$ ) for each spatial window (e.g. PC1 $1_{\text {water }}$ PC2 ${ }_{\text {water }}$ PC $3_{\text {water }}$ PC4 $4_{\text {water }}$ and $\left.\mathrm{PC} 5_{\text {water }}\right)$. Such a dimension reduction analysis did not systematically remove collinearity across groups of variables for each spatial window (Figure S1). As such, we identified pairs of variables still highly correlated $\left(R^{2}>0.8\right)$ (e.g. $P C 1_{\text {water }}$ and $P C 1_{\text {atmosphere }}$ in
TABLE 2 The parameter ranges searched during the hyperparameter optimization

\begin{tabular}{|ll}
\hline Parameter & $\begin{array}{l}\text { Search } \\
\text { range }\end{array}$ \\
\hline learning_rate & $(0.1,0.01)$ \\
\hline max_depth & $(5,7,10)$ \\
\hline min_child_weight & {$[1,3,5]$} \\
\hline subsample & {$[0.5,0.7,0.9]$} \\
\hline colsample_bytree & {$[0.5,0.7,0.9]$} \\
\hline n_estimators & {$[300,500]$} \\
\hline gamma & {$[0,0.5,1]$} \\
\hline
\end{tabular}

Figure S2). In the example shown in Figure S2, we first trained an XGBoost model without $P C 1_{\text {water }}$ and then another XGBoost mode without $P C 1_{\text {atmosphere }}$ in order to make sure that the contribution of $P C 1_{\text {water }}$ would not be attenuated by the presence of $P C 1_{\text {atmosphere }}$ in the set of input variables and vice-versa. We performed the variable importance analysis described below for those two trained models (for which collinearity issue was assumed to be controlled for) independently. Each XGBoost model was trained on $70 \%$ of the available pixels randomly selected in each spatial window (i.e. training sets) (Figure 1b). For each model, we did a grid search of the hyper-parameters (Table 2 ), and we used $1 / \sigma_{\text {NABP }}$ as weights during the training procedure to ensure that the NABP estimates with high uncertainties were considered less important during the training of each model.

To quantify the contribution of each input variable to the prediction of NABP, we used the Tree SHapley Additive exPlanations (TreeSHAP) algorithm (Lundberg et al., 2019; Lundberg \& Lee, 2017). We retrieved a SHAP value for each time step and each pixel to understand the impact 
of the environmental conditions on NABP in time and space. Once several XGBoost models were trained within each $25 \times 25$ spatial window because of remaining collinearity after the dimension reduction, we computed the SHAP values independently for all the trained models. The final SHAP values for each input variable were the maximum set of computed SHAP values. A negative SHAP value for a given variable $X$ translated as a negative contribution to the local changes of NABP in time and vice-versa. For instance, a negative value for $\mathrm{PC} 1_{\text {atmosphere }}$ reflected its contribution to increasing carbon losses locally, while on the other hand, a positive SHAP value reflected its contribution to carbon gains. To quantify the contribution of each group of variables to carbon gains and losses, we computed the sum of the absolute SHAP values for each pixel independently for all the input variables related to the atmosphere, water-related and vegetation groups respectively. These relative importance estimates were also summarized at the biome level: boreal forests, temperate forests, tropical forests and tropical savannas (Beer et al., 2010).

Model performance was also computed on the test sets (i.e. the left out $30 \%$ pixels within the spatial window) using the root-meansquare error (RMSE) and Nash-Sutcliffe model efficiency coefficient (NSE) to ensure the robustness of the retrieved SHAP values. Spatial windows with NSE estimates lower than or equal to 0 were discarded.

\subsection{Covariation of forest carbon changes with net $\mathrm{CO}_{2}$ fluxes}

We compared atmospheric inversion-based NBP estimates with NABP estimates for the period 1993-2018. The comparison of NABP against NBP was conducted over the 14 GFED regions (Giglio et al., 2013) (Figure S17). For each GFED region, we calculated an area-weighted sum of annual NBP from the daily estimates and further derived spatial mean NBP estimates representing 19932018. Area-weighted sums of annual AGB were computed at the regional scale (i.e. GFED regions) for the same period. Area-weighted sums of annual NABP estimates were further computed from the area-weighted sums of annual AGB. Herewith, we compared the long-term mean of NABP with long-term mean NBP to understand whether long-term forest growth covaried with long-term carbon sink. In addition, we compared the long-term standard deviation of NABP with a long-term standard deviation of NBP to understand whether the year-to-year variability of forest carbon changes covaried with the year-to-year variability of NBP.

\section{3 | RESULTS}

\subsection{Global patterns of forest carbon changes}

Figure 2a,b show the spatial patterns of carbon losses and gains during 1992-2018. The arc-of-deforestation in South America, the Congo basin and Southeast Asia, and Central Europe experienced substantial carbon gains and losses. On the other hand, the humid part of the Amazon or the Sahel did not experience substantial carbon gains or losses. The analysis of NABP as a function of the previous year $A G B\left(A G B_{t-1}\right)$ indicated that $A G B$ changes were associated with the amount of carbon stored in a forest (Figure 2c,d). Generally, our results revealed that regions with carbon stocks ranging from 50 to $125 \mathrm{MgC} \mathrm{ha}^{-1}$ showed both the highest carbon losses and carbon gains in absolute terms (Figure $2 \mathrm{c}$ ). Figure $2 \mathrm{~d}$ shows a gradual decline of forest carbon gains and losses relative to the carbon stocks of the previous year with increased carbon stocks. As expected, forests with the highest carbon stocks (i.e. AGB class $>125 \mathrm{MgC} \mathrm{ha}^{-1}$ ) did not have the highest carbon gains both in absolute and relative terms (Figure 2c,d).

While the magnitudes of carbon gains and losses were generally similar on average within each AGB class (Figure 2c,d), differences were apparent at the local scale (Figure 2e,f). For instance, carbon losses in correspondence with the arc-of-deforestation around the Amazon or the Congo basin were more significant than carbon gains (i.e. red colour in Figure 2e). Temperate European forests instead were characterized by a net carbon gain (i.e. blue colour in Figure 2e). In relative terms, arid and semi-arid regions revealed more carbon gains than carbon losses for the same period (i.e. blue colour in Figure 2f). Tropical forests had the most significant carbon gains (Figure S3a) and losses (Figure S3b), followed by temperate forests, boreal forests and tropical savannas at the biome level.

\subsection{Sensitivities of forest carbon changes to environmental conditions across scales}

Globally, NABP correlated positively with forest cover fraction ( $r=0.65)$ (Figure 3a), Pdep $(r=0.41)$ (Figure 3f), IWA $(r=0.42)$ (Figure 3i), solar radiation ( $r=0.35$ ) (Figure 3o) and temperature $(r=0.29)$ (Figure $3 \mathrm{k}$ ), while NABP correlated negatively with precipitation $(r=-0.44)$ (Figure $3 g$ ). Unlike Pdep, Ndep had a low correlation with NABP $(r=0.04)$ (Figure 3e). Interestingly, higher carbon losses occurred when the recent-past $A G B$ estimates were lower (i.e. $\left.A_{G B} B_{\text {lag2 }}\right)(r=-0.60)$ (Figure $\left.3 b\right)$. On the other hand, the relationship between GPP and NABP and between RECO and NABP, although negative, was rather scattered ( $r=-0.27$ and $r=-0.12$ respectively) and not significant (Figure 3c,d).

Another finding was the lagged effects of atmospheric conditions on the global temporal NABP dynamics. For instance, we observed that years with higher atmospheric water demands (i.e. $V_{P D_{\text {lag2 }}}$ ) (Figure $3 n$ ) were somewhat associated with higher forest carbon gain the subsequent year, although the correlation was relatively moderate $(r=0.36)$ and not significant $(p>.05)$. Similarly, we observed that higher temperature during a preceding year (i.e. temperature $\left._{\mathrm{lag} 2}\right)$ moderately stimulated forest growth the subsequent year $(r=0.38)$, although the relationship was not significant $(p>.05)$ (Figure 31).

The observed global relationships (Figure 3) did not systematically hold at the local scale (Figure 4). Figure 4a shows a tendency 


\section{(a)}

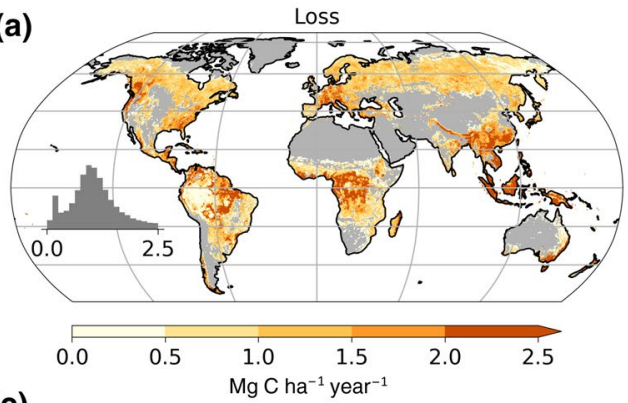

(c)

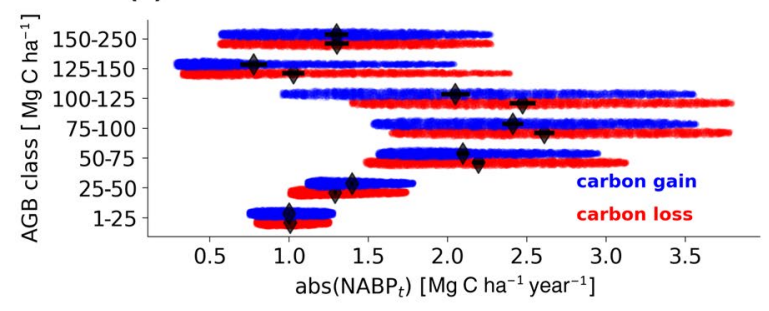

(e)

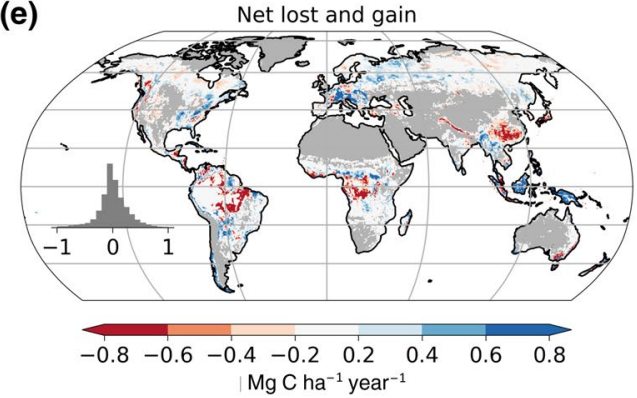

(b)

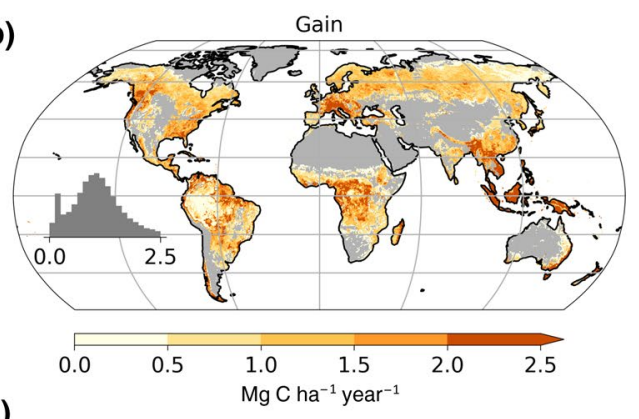

(d)

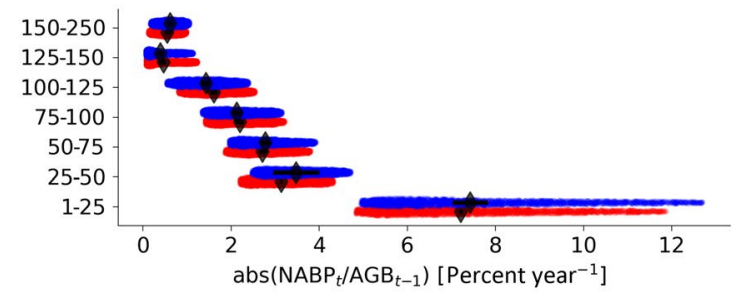

(f)

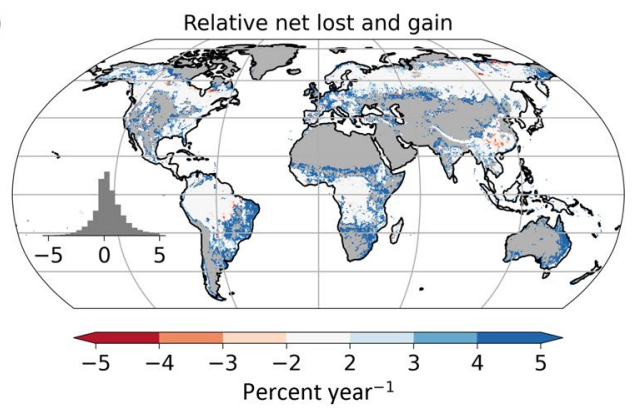

FIGURE 2 Geographical distributions of forest carbon gains (c) and losses (b) for the period 1992-2018. The absolute values of median estimates of years with NABP $<0$ and years with NABP $>0$ for each pixel are shown. The absolute values of median loss and gain estimates are also shown across a series of AGB classes for the period 1992-2018 ( $c$ and d) as well as the absolute and relative mean NABP (e and f). In $d$ and $f$, median estimates of NABP for each pixel relative to $A G B_{t-1}$ were used. The error bars in $c$ and $d$ represent spatially aggregates of $\sigma \mathrm{NABP}$ for each AGB class. The quantile $5 \%$ of the forest cover fraction derived from the ESA-CCl dataset for the period $1992-2018$ was used to mask out the pixels with quantile estimates below $20 \%$ of forest fraction

for increased forest cover fraction with forest growth with a median correlation of 0.2 . Similarly, we found that a fraction of the forested ecosystems depicted a negative correlation between NABP and recent-past $A G B$ (i.e. $A G B_{\text {lag2 }}$ ), particularly in regions with high rates of deforestation (e.g. Amazon arc-of-deforestation, Congo Basin, South-East Asia) (Figure 4b). Few regions had a positive relationship between GPP and NABP (i.e. parts of the Amazon and the Miombo region) (Figure 4c). Interestingly, we also found that hot and dry conditions had a widespread positive effect on the subsequent forest growth. More precisely, we observed that $\mathrm{VPD}_{\text {lag2 }}$ (Figure $4 \mathrm{i}$ ) and temperature $_{\text {lag2 }}$ (Figure $4 \mathrm{k}$ ) were positively correlated with NABP, which confirmed the findings observed on the global weighted averages (Figure $3 \mathrm{i}$ and Figure $3 \mathrm{k}$ ). In some parts of the Amazon and the Sahel, we observed an increase in temperature (Figure 4j) or VPD (Figure 4h) corresponding to higher losses in forest carbon stocks. (Figure 3j,h). Furthermore, an increase in precipitation positively correlated with increased forest carbon stocks for regions such as the Southeast part of China and the Western part of Siberia (Figure 4f). A widespread positive correlation was also found between NABP and a proxy for soil water availability (Figure $4 \mathrm{~g}$ ). The sensitivities of NABP to changes in Pdep and Ndep differed locally, with regions either having positive or negative relationships between NABP dynamics and Pdep or Ndep (Figure 4d,f). For instance, we observed an increase in Ndep in some regions, for example, a small part of the Congo basin, a small part of the Sahel and parts of Europe. On the other hand, we observed negative correlations between Pdep and NABP in regions such as the Amazon basin and North American boreal forests.

Figure 5 shows net NABP for the period 1992-2018 across hydrometeorological and vegetation regimes. Interestingly, long-term forest carbon gains were identified in hot and dry regions, while very wet and cold regions had long-term forest carbon losses (Figure 5a). Similarly, regions with high atmospheric water demand and solar radiation depicted long-term forest carbon gains (Figure $5 b$ ).

Regions with high Ndep but low Pdep had long-term forest carbon losses, possibly indicating an adverse effect of Ndep on NABP when Pdep is limited (Figure $5 c$ ). Such adverse effects of Ndep on NABP appeared to be mainly located in China/East Asia. 

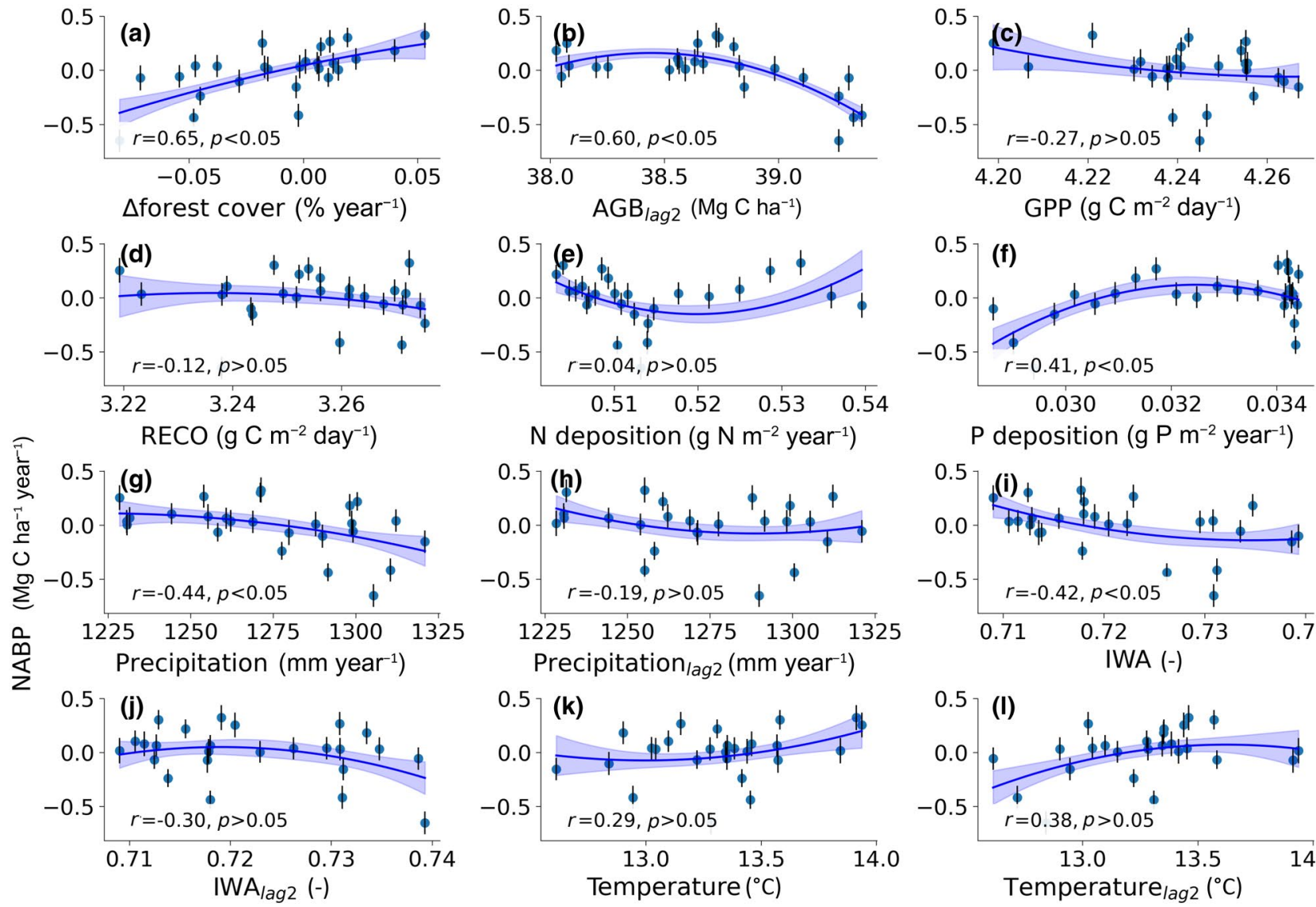

$\mathrm{N}$ deposition $\left(\mathrm{g} \mathrm{N} \mathrm{m}^{-2}\right.$ year $\left.^{-1}\right)$
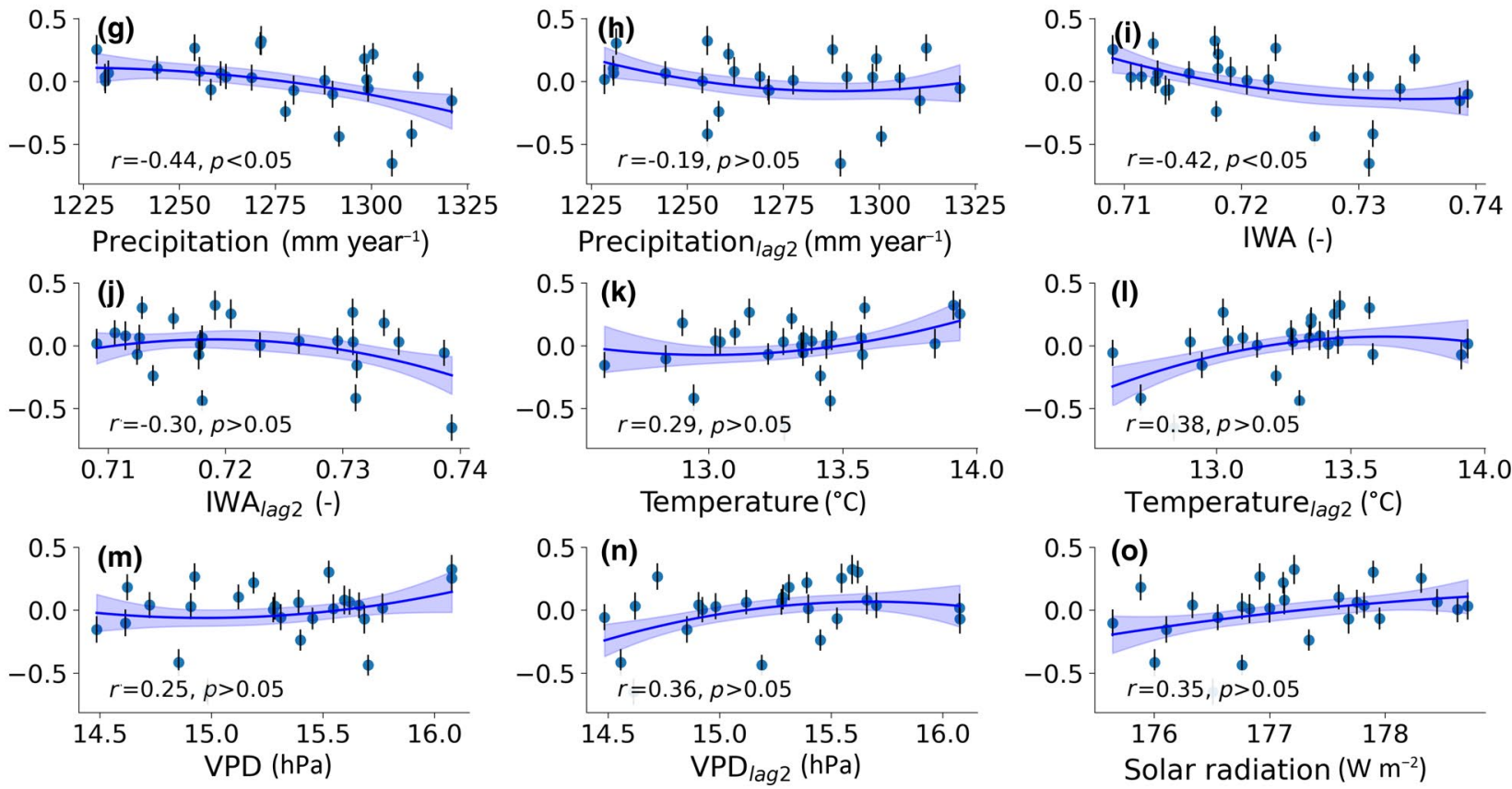

FIG URE 3 Bivariate relationship between the global signals of annual NABP and annual $\Delta$ forest cover (a), AGB $\mathrm{lag}_{\text {lag }}$ (b), annual mean GPP (c), annual mean RECO (d), annual mean Ndep (e), annual mean Pdep (f), total annual precipitation (g), total annual precipitation lag2 $_{2}(\mathrm{~h})$, annual mean SM layer 1 (i), annual mean IWA $\mathrm{lag}_{2}(\mathrm{j})$, annual mean air temperature (K), annual mean air temperature $\operatorname{lag}_{2}(\mathrm{~L})$, annual mean VPD (M), annual mean $\mathrm{VPD}_{\operatorname{lag} 2}(\mathrm{~N})$ and annual mean global radiation (o). The blue ribbon depicts the uncertainty in estimating the fitting polynomial parameters inferred from the covariance matrix and weighted by $1 / \sigma$ NABP. Each dot represents an area-weighted global estimate for a year. The error bars represent an area-weighted global estimate of $\sigma$ NABP at global scale for each year. The quantile $5 \%$ of the forest cover fraction derived from the ESA-CCI dataset for the period 1992-2018 was used to mask out the pixels with quantile estimates below $20 \%$ of forest fraction

Long-term forest carbon gains were observed in regions with low forest area fractions spanning a wide tree cover range. Conversely, regions with high forest fraction and high tree cover or low tree cover depicted long-term forest carbon losses (Figure $5 \mathrm{~d}$ ). Increased GPP appeared to promote long-term forest growth up to a point where high photosynthesis was coupled with high ecosystem respiration, where we observed long-term forest carbon losses (Figure 5e). Finally, our results showed that regardless of the forest fraction, the lower the recent-past carbon stocks, the higher the forest carbon gains, whereas high recentpast carbon stocks were associated with long-term forest carbon losses (Figure 5f).

\subsection{Main environmental condition controls on forest carbon changes}

Using a model attribution technique (see Section 2.4 in the method section), we investigated the importance of atmosphere, waterrelated and vegetation conditions in controlling NABP temporal dynamics at pixel and biome levels (Beer et al., 2010) (Figure 6). Globally, we observed that atmosphere conditions had the most controls on NABP, followed by water-related and vegetation conditions. More specifically, atmosphere, water related and vegetation were the dominant factors controlling NABP for $56 \%, 29 \%$ and $15 \%$ of the total forested land area respectively. The dominant controls 


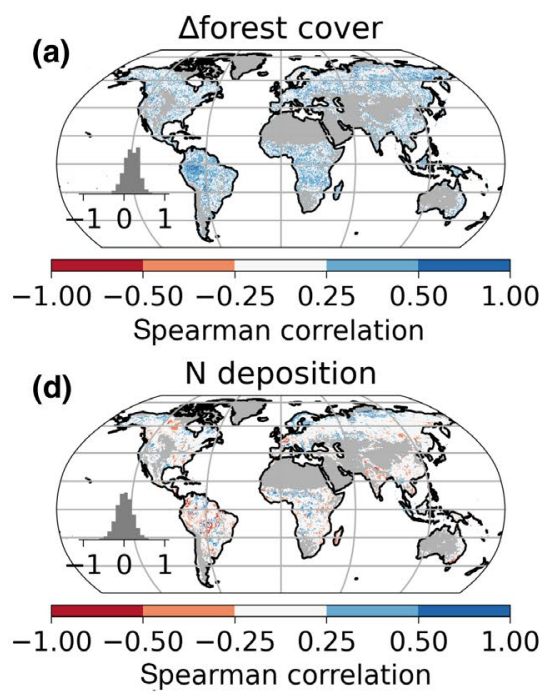

(g)

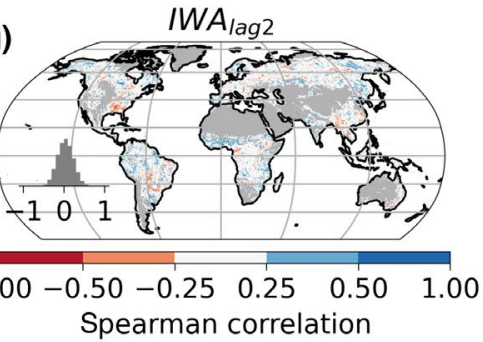

Temperature

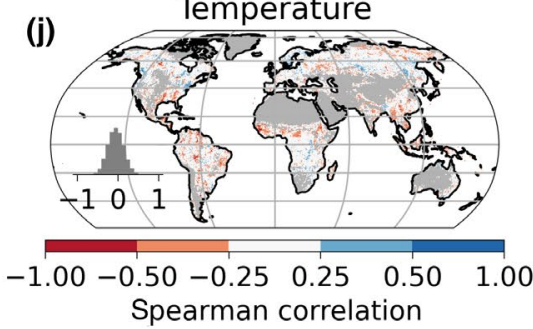

(b)

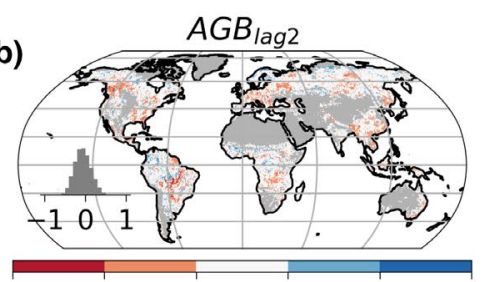

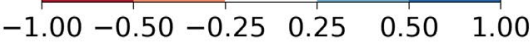

Spearman correlation

(e)

$P$ deposition

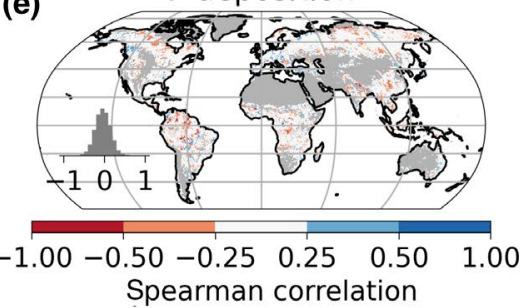

VPD

(h)

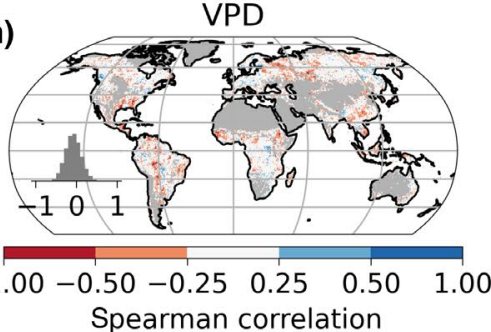

(k)
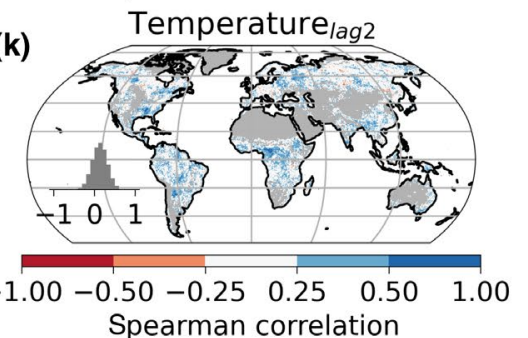

(c) GPP

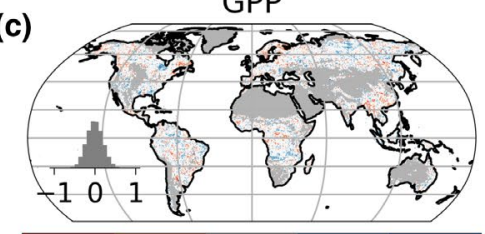

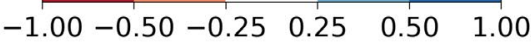

Spearman correlation

(f)

Precipitation

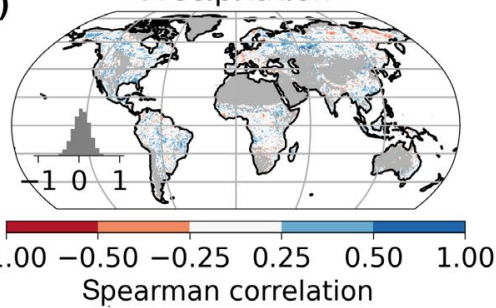

(i) $\quad V P D_{\operatorname{lag} 2}$

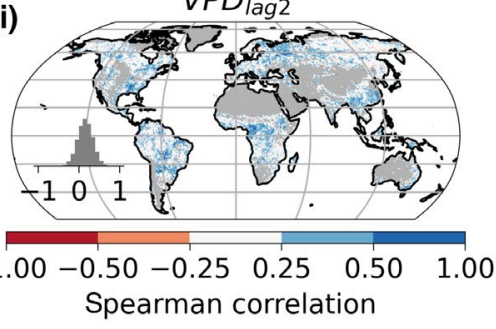

Solar radiation

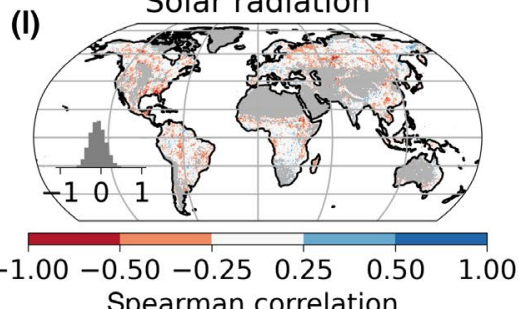

FIGURE 4 Correlation maps at pixel level between annual NABP and $\triangle$ forest cover (a), AGB lag2 $_{2}$ (b), GPP (c), Ndep (d), Pdep (e), precipitation (f), IWA $\mathrm{Iag}_{2}(\mathrm{~g}), \mathrm{VPD}(\mathrm{h}), \mathrm{VPD}_{\operatorname{lag} 2}(\mathrm{i})$, temperature $(\mathrm{j})$, temperature $\mathrm{lag}_{2}(\mathrm{k})$ and solar radiation (I). Spearman's rank correlation coefficients are shown. The quantile 5\% of the forest cover fraction derived from the ESA-CCI dataset for the period 1992-2018 was used to mask out the pixels with quantile estimates below $20 \%$ of forest fraction

of water-related conditions on NABP were mainly observed in the semi-arid to arid regions, while the dominant controls of vegetation were primarily apparent in the Amazon basin, particularly in the arcof-deforestation (Figure 6a). Furthermore, we observed significant trends in time locally for both atmosphere, water-related and vegetation conditions (Figure S9). For instance, positive trends in the sensitivities of NABP to atmosphere conditions were observed in the humid part of the Congo basin, while there were negative trends in some parts of the dry tropics (Figure S9a). On the other hand, NABP appeared less sensitive to water-related conditions with time in part of the Miombo woodlands and large parts of Central Europe (Figure S9b). Finally, we also observed significant negative trends in the sensitivities of NABP to vegetation conditions (Figure S9c).

In boreal and temperate forests, we found that the variables related to atmosphere had substantial control on NABP temporal dynamics both for positive and negative SHAP values, followed by water-related and vegetation conditions (Figure $6 \mathrm{c}$ ). In tropical ecosystems, atmosphere conditions appeared to be similarly important factors for negative SHAP values, while vegetation conditions had the strongest controls on carbon gains (i.e. positive SHAP values) in tropical regions.

Across the hydrometeorological regime, we observed that the atmospheric conditions substantially controlled NABP in a wide range of temperature and water availability conditions (Figure 7a). Similarly, Figure $7 \mathrm{~b}$ shows that the atmospheric conditions had substantial controls on NABP in a wide range of forest fractions, particularly in regions with high tree cover. Like atmospheric conditions, water-related conditions controlled NABP in a wide range of hydrometeorological conditions, outside arid and warm regions (Figure $7 \mathrm{~b}$ ) and regions with high tree cover (Figure 7e). Finally, vegetation conditions had strong controls on NABP in relatively warm and wet regions (Figure 7c). In contrast, vegetation contributed substantially to NABP in regions with high tree cover (>50\% tree cover) while spanning a wide range of forest area fractions (Figure $7 f$ ). 

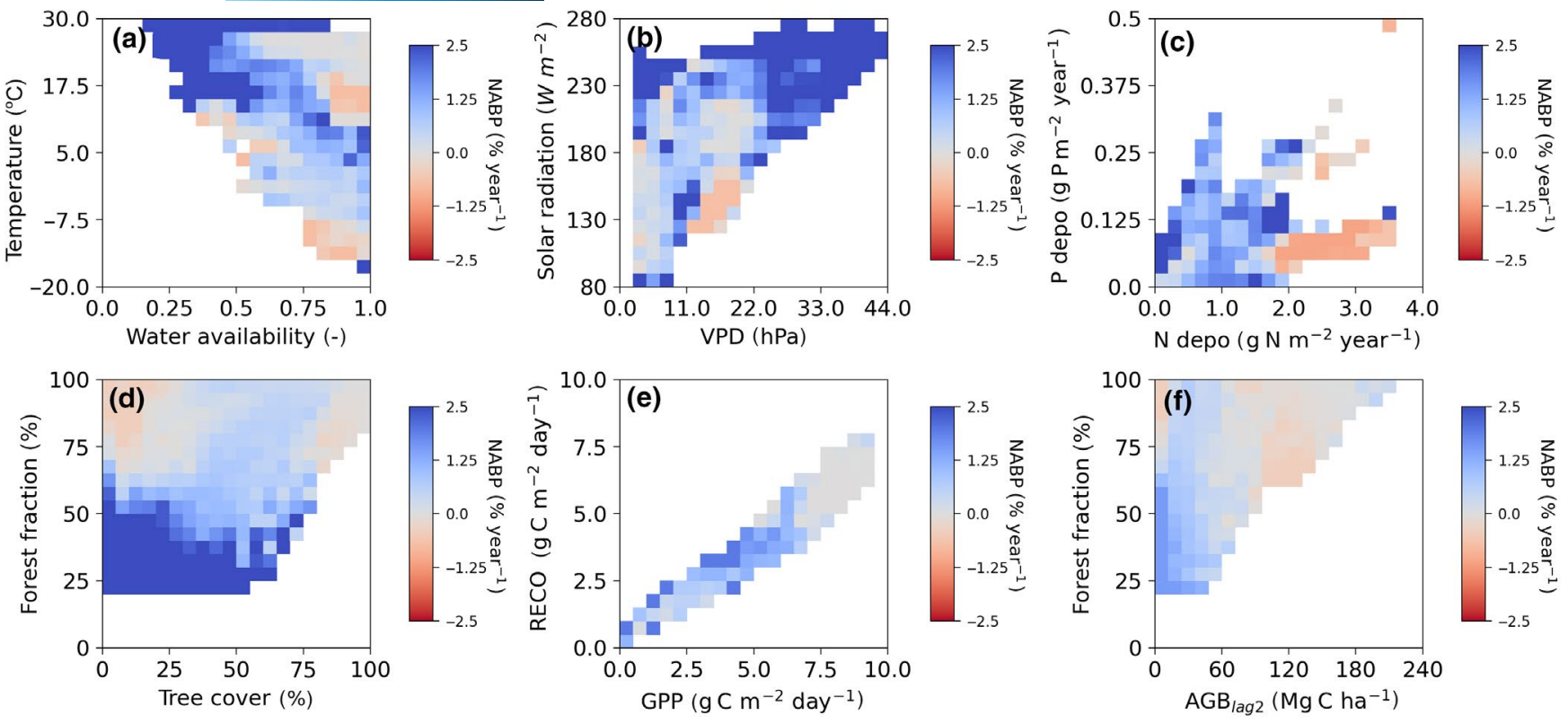

FIG URE 5 NABP across hydrometeorological and vegetation regimes. The colour bar represents the net NABP relative to AGB $\mathrm{t}_{\mathrm{t}-1}$ for the period 1992-2018. A median estimate of net NABP for each bin is shown. Bins containing less than 10 data points were filtered out

(a)

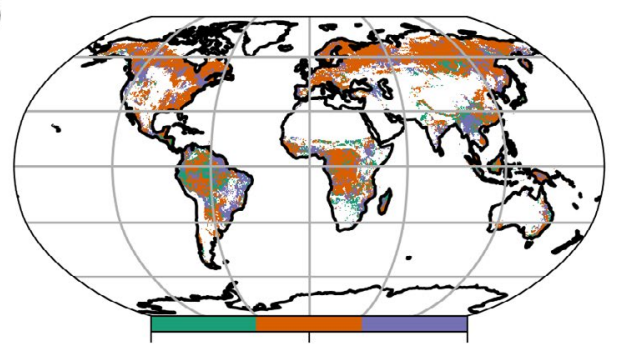

Vegetation Atmosphere Water

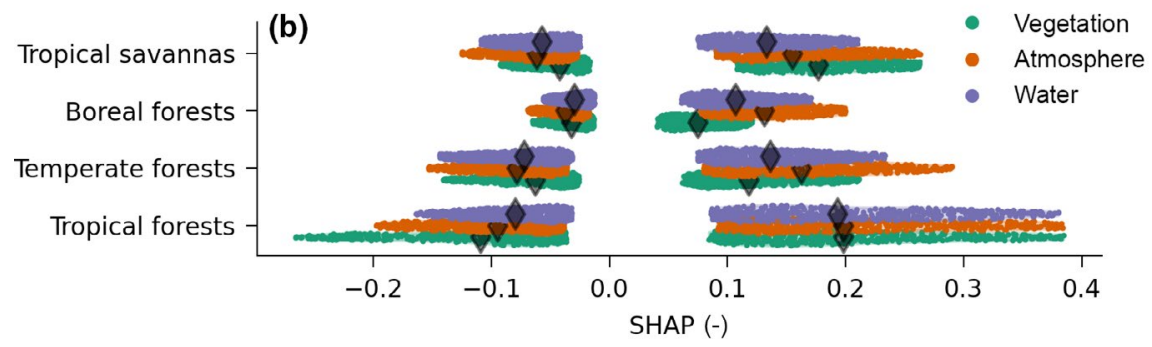

FIGURE 6 Dominant variable group in predicting temporal NABP dynamics (i.e. atmosphere, water related and vegetation) at pixel level (a). Violin plots of the SHAP values for vegetation, atmosphere and water-related conditions across biomes (b) are also shown. To compute the dominance of each group at pixel level, we first computed the median absolute SHAP values in time at pixel level for each variable and we further grouped and summed the median absolute SHAP values of the variables belonging to the atmosphere, water-related or vegetation group (see Table 1). The dominant group at pixel level, therefore, represents the group of variables with the highest summed values. The quantile $5 \%$ of the forest cover fraction derived from the ESA-CCl dataset for the period 1992-2018 was used to mask out the pixels with quantile estimates below $20 \%$ of forest fraction

\section{4 | Relating forest carbon gain/loss and net $\mathrm{CO}_{2}$ uptake}

We analysed the relationship between the long-term mean in NABP and the long-term mean in net $\mathrm{CO}_{2}$ fluxes between the land and atmosphere from inversions of atmospheric $\mathrm{CO}_{2}$ across GFED regions (Figure 8a and Figure S11). We generally found that regions with long-term growth were associated with long-term carbon sinks and vice-versa. While we observed both a carbon sink strength (i.e. negative NBP) and a positive trend in LAI in the Central Asian region (i.e. CEAS) (Figure S12), there was a long-term forest net carbon 

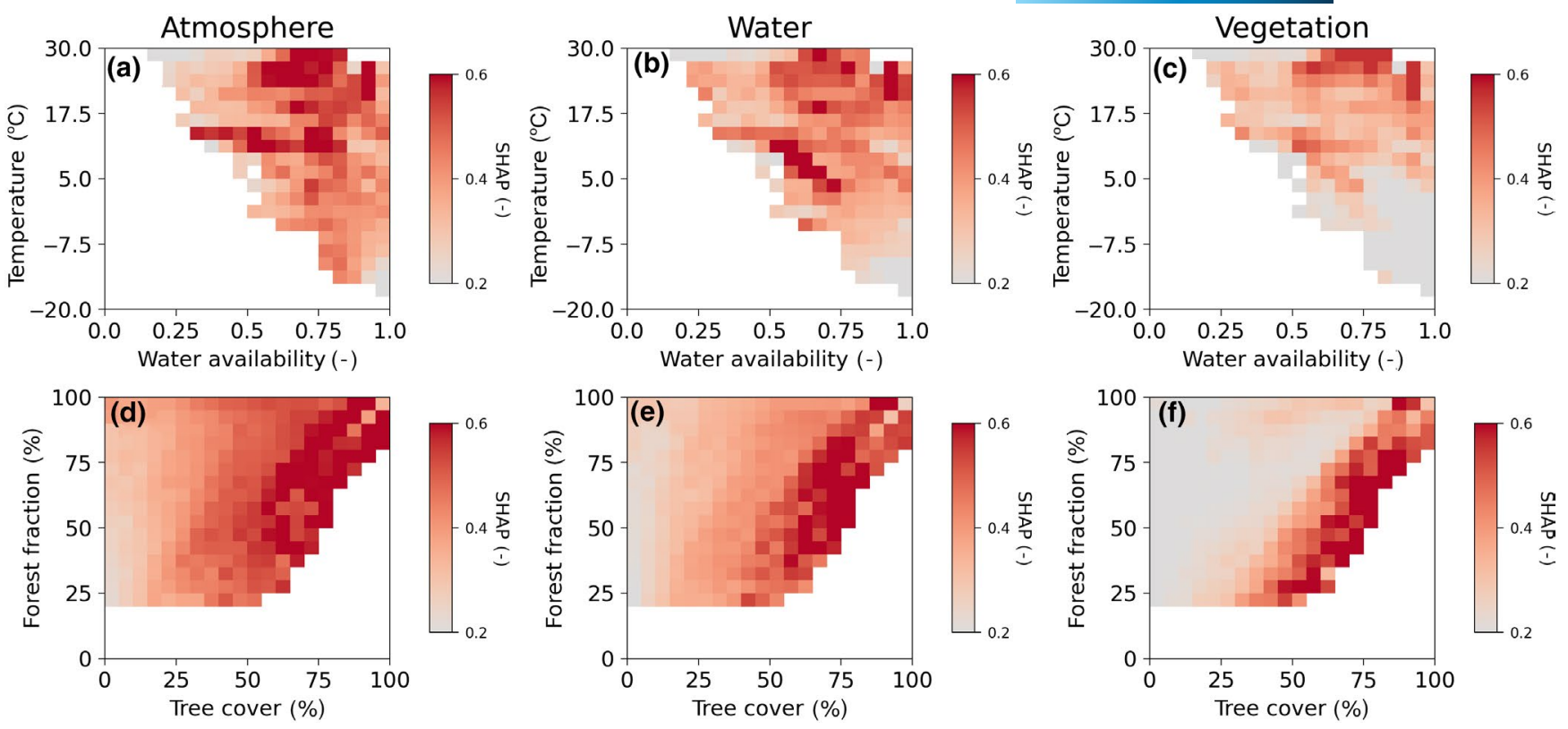

FIGURE 7 Atmosphere, water and vegetation controls on NABP across hydrometeorological and vegetation regimes. The colour bar represents the absolute sum of the SHAP corresponding to each group of variables. Temperature-water availability and forest fractiontree cover were used to represent hydrometeorological and vegetation regimes respectively. Tree cover estimates were collected from the Hansen tree cover data (Hansen et al., 2013) and averaged from a $30 \mathrm{~m}$ pixel to a $0.25^{\circ}$ pixel size. A median estimate of the SHAP values for each bin is shown. Bins containing less than 10 available data points were filtered out
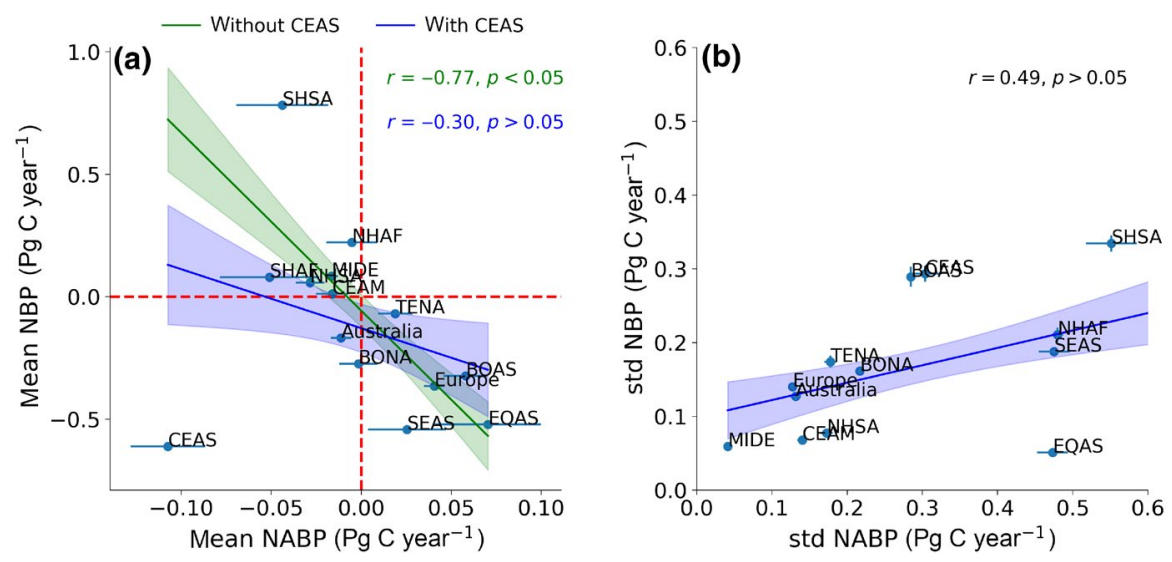

FIG URE 8 Relationship between mean NBP and mean NABP (a) and between the standard deviation (std) of NBP and the standard deviation of NABP (b) across the 14 GFED regions. Each dot represents either long-term mean of NBP and NABP or long-term standard deviation of NBP and NABP for one of the GFED regions. Uncertainties presented in the error bars were computed by randomly removing 4 years before computing the NABP and NBP means or the NABP and NBP standard deviations for each region. This procedure was done 12 times while we ensured that for every iteration a different set of years was removed. AUST, Australia; BOAS, Boreal Asia; BONA, Boreal North America; CEAM, Central America; CEAS, Central Asia; EQAS, Equatorial Asia; EURO, Europe; MIDE, Middle East; NHAF, Northern Hemisphere Africa; NHSA, Northern Hemisphere South America; SEAS, Southeast Asia; SHAF, Southern Hemisphere Africa; SHSA, Southern Hemisphere South America; TENA, Temperate North America

loss (i.e. negative NABP) for the period 1992-2918. By removing the CEAS region when comparing the long-term mean in NABP and the long-term mean in net $\mathrm{CO}_{2}$ fluxes, we found a significant correlation of 0.77 compared to a non-significant correlation of 0.3 when the CEAS region was included.

Interestingly, the magnitudes of carbon losses and gains were substantially lower than the carbon sinks and sources' magnitudes observed by the atmospheric inversion product (Figure 8a) (residuals ranging from -0.8 to $0.6 \mathrm{PgC}_{\text {year }}{ }^{-1}$ ). While the mean NBP was substantially higher than the magnitude of mean NABP in most of the GFED regions, their standard deviations appeared to have a relatively similar order of magnitude (Figure $8 \mathrm{~b}$ ), which suggested an association between NBP and NABP year-to-year variabilities. More precisely, regions with high year-to-year variabilities in NABP were coupled with regions having high year-to-year variabilities in NBP $(r=0.49, p>.05)$. 


\section{DISCUSSION}

\subsection{Global patterns of forest carbon changes}

Our study revealed that forests with the highest carbon stocks (i.e. $150-250 \mathrm{MgC} \mathrm{ha}^{-1}$ ) did not have the highest carbon gains (Figure 2c,d), confirming that older/mature forests do not have the highest capacity to produce biomass and that highly stocked forests are also closer to steady state (Odum, 1969). Likely, mature forests with high carbon stocks have reached late successional stages and have a low potential for storing carbon from the atmosphere (Musavi et al., 2017). However, we do observe high carbon stock forests gaining carbon, consistent with the fact that mature forests maintain the capacity to grow and absorb carbon dioxide from the atmosphere (Luyssaert et al., 2008) (Figure 1c, AGB class $>150 \mathrm{MgC} \mathrm{ha}^{-1}$ ). Our results also indicated that the forests with carbon stocks $>150 \mathrm{MgC}$ $\mathrm{ha}^{-1}$ experienced lower carbon losses than a forest with intermediate carbon stocks (125-150 $\mathrm{MgC} \mathrm{ha}^{-1}$ ), which could signify that mature forests are possibly less sensitive to changes in environmental conditions, although it has been shown globally that mature forests exhibited greater decreases in growth rate during drought (Bennett et al., 2015; Stovall et al., 2019). Another explanation could be that forest logging is less intense in areas with high carbon stocks in remote, dense forest areas. However, these findings were affected by the weak sensitivity of the C-band backscatter observations in high biomass forest (Cartus et al., 2019; Santoro et al., 2019); therefore, NABP estimates in the largest AGB class might have been smaller than in reality. Finally, the lowest AGB class was strongly impacted by an offset when the forest fraction is about $20-30 \%$ or less, possibly underestimating AGB and affecting the NAPB estimates in such regions.

In large parts of Europe, we observed an overall carbon gain for 1992-2018 (Figure 2e). In the last decades, the increasing AGB in Europe has mainly been ascribed to improved forest management practices and forest area expansion, combined with changes in Ndep and $\mathrm{CO}_{2}$ fertilization (Etzold et al., 2020). However, a recent slowdown in forest growth attributed to the fact that European forests are increasingly mature and have reached late successional stages (Nabuurs et al., 2013), a reduction in Ndep in Europe (de Vries et al., 2011), and an increased number and intensity of climate-extreme events (Piao et al., 2019) might result in a negative NABP in the coming decades. We observed that around the Amazon or the Congo basin, there were higher carbon losses than carbon gains for the period 1992-2018, which are very likely related to high rates of deforestation or forest degradation reported in these regions (Achard et al., 2014; Hansen et al., 2013) and to carbon loss during extreme El Niño events (Brienen et al., 2015; Fan et al., 2019; Wigneron et al., 2020). Although one of the world's major deforestation hotspots (Achard et al., 2014; Hansen et al., 2013; Miettinen et al., 2011), the data for tropical Asia presented an overall carbon gain for the last three decades, suggesting that carbon losses via deforestation could have been mitigated by re-growing secondary forests (Achard et al., 2014; Stibig et al., 2014). In line with the general recognition of North American forests acting as a carbon sink (Pan et al., 2011), we observed either a positive or neutral net NABP in the Northern American Boreal and Temperate regions. Negative NABP estimates were also observed locally that could be associated with fire regimes (Zhao et al., 2021).

\subsection{Sensitivities of forest carbon changes to environmental conditions}

While we did not observe significant relationships between NABP and air temperature (Figure 3j) or VPD (Figure 3h), we found locally that an increase in air temperature (Figure 4j) or VPD (Figure 4h) could result in higher losses in forest carbon stocks. The adverse effects of higher temperatures on forest growth observed locally could suggest a temperature-dependent increase in autotrophic respiration and temperature-dependent reductions in carbon assimilation (Hubau et al., 2020). More precisely, reductions in carbon assimilation in hot and dry conditions are related to hydraulic stress (Fontes et al., 2018), stomatal closure, and consequently, carbon starvation due to limited photosynthesis (McDowell et al., 2018). High levels of VPD generally increase the demand for evaporation, potentially leading to low soil moisture and dryness stress on vegetation, which can drive widespread tree mortality (Allen et al., 2015). At the same time, we observed that long-term forest growth occurred in hot regions or with high atmospheric dryness (Figure $5 \mathrm{a}$ ), which could confirm that forest biomass tends to increase with warmer and higher atmospheric water demand (Green et al., 2020), which might suggest a decrease in autotrophic respiration with increasing temperature (Collalti et al., 2020).

Interestingly, we found that the VPD conditions of the previous year (i.e. $V P D_{\text {lag2 }}$ ) can have a widespread control on NABP temporal dynamics (Figure 4i), suggesting a legacy effect of atmospheric dryness on forest carbon changes. On the one hand, high levels of VPD can result in tree mortality and carbon loss because of stomatal closure and photosynthesis reduction (Cowan \& Farquhar, 1977; Konings \& Gentine, 2017). The negative sensitivity of forest growth to increases in VPD during a preceding year could result in higher forest growth in the subsequent year. This assumption could indicate regrowth responses and recovery, therefore forest carbon growth, after adverse atmospheric dryness conditions.

While in the global weighted averages, increased rainfall was associated with lower forest growth (Figure $3 g$ ). We observed locally that an increase in forest carbon stocks could sometimes co-occur with an increase in annual precipitation and recent-past soil water availability (Figure 4f,g). These observed emergent relationships between NABP and water-related variables could suggest that having more water available, therefore less evaporative stress, could enhance photosynthesis and hence carbon gains (Lin et al., 2015). We also found to a lower extent that wetter years can reduce forest growth which could be related due to decreased $\mathrm{CO}_{2}$ diffusion in wet leaves (Ishibashi et al., 1996) and increased cloud coverage, reducing incoming solar radiation. Water-limited regions depicted 
higher long-term forest growth in relative terms compared to nonwater-limited regions (Figure 5a). Forest ecosystems in such arid and semi-arid regions appeared to have sufficient access to groundwater through their root system to maintain their growth.

A recent meta-analysis of Ndep fertilization studies has shown that an increase in Ndep increased aboveground woody biomass in boreal and temperate forests but had no significant effect in tropical forests due perhaps to more pressing $\mathrm{P}$ limitation (Schulte-Uebbing $\&$ Vries, 2018). Here, Pdep or Ndep had variable controls on NABP at a local scale (Figure 4d,f). Yet, globally increased Pdep is associated with increased NABP (Figure 3f), revealing an association of P limitation with a decrease in carbon stocks in forest ecosystems. $P$ and $\mathrm{N}$ fertilization effects on changes in AGB dynamics are expected to occur at a longer timescale than the annual scale due to strong competition by soil aggregates and soil microorganisms for new nutrient inputs (Templer et al., 2012). This could explain the weak relationship found in this study between Pdep or Ndep and NABP locally at the annual scale. We found a relatively strong positive link between the long-term increase in Ndep or Pdep and the long-term increase in carbon stocks locally (Figure S5a and S5b). Another aspect is the phytotoxic effects of high Ndep, such as acid rain in East Asia, which has led to enhanced soil acidification (Liu et al., 2010), resulting in a nonlinear Ndep effect on forest growth (Högberg, 2007). We observed that under low Pdep and very high Ndep conditions, forests generally lost carbon during the last three decades (Figure $5 \mathrm{c}$ ), particularly in the Central Asia region (Figure S18). These findings have to be taken with care, although, knowing that such Ndep and Pdep modelled estimates derived from chemistry transport models (Wang et al., 2017) appeared to be highly correlated with climate variables (Figure S6 and S7), therefore confounding effects between climatic conditions and either Ndep or Pdep might have occurred. They could challenge the observed local links between the long-term trends in Pdep or Ndep and NABP.

Surprisingly, we observed that GPP had limited controls on NABP variability, indicating that increased productivity via photosynthesis was not directly associated with increased carbon stocks (Figure $3 c$ and $4 c$ ). The low sensitivity of forest carbon gains to increased productivity could suggest that forest carbon changes may be controlled by allocation and carbon loss mechanisms (e.g. mortality and respiration) through, for instance, enhancement of respiration from rising air temperature. Although long-term forest growth increased with increased levels of photosynthesis, we also observed that conditions with very high levels of both ecosystem respiration and photosynthesis resulted in long-term forest carbon losses (Figure 5e), indicating lower biomass production efficiency for high GPP coupled with high RECO. By correlating NABP with GPP derived from the Fluxcom GPP-RS product, we did not find a widespread positive correlation between GPP and NABP at the pixe level (Figure S1), confirming that GPP is not systematically coupled with forest growth (Figure $3 \mathrm{c}$ and $4 \mathrm{c}$ ). However, the FLUXCOM GPP products used in our analysis did not include $\mathrm{CO}_{2}$ fertilization effects and only included the trends associated with meteorological variables in the GPP FLUXCOM estimates (Jung et al., 2020).
As such, $\mathrm{CO}_{2}$ fertilization effects on photosynthesis (Schimel et al., 2015) were not considered in our analysis and could dampen the control of GPP on NABP.

While the sensitivities of NABP to the changes in forest fraction are typically strongly positive (Figure $3 a$ and Figure $4 a$ ), we also found that NABP appeared to be relatively sensitive to the recentpast carbon stocks (i.e. $\mathrm{AGB}_{\text {lag2 }}$ ) both globally (Figure $3 \mathrm{~b}$ ) and locally (Figure 4b). The emergent relationship between $\mathrm{AGBI}_{\mathrm{ag} 2}$ and NABP was negative, suggesting that the lower the recent-past carbon stock of forests was, the more forests gained carbon. Such findings confirm that there may be a decrease in biomass production as forests age (Collalti et al., 2020). Such observations occurred in a wide range of forest fractions (Figure 5f). To a lower extent, we observed that an increase in LAI (i.e. $\Delta \mathrm{LAI}$ ) was coupled with a local forest growth (Figure S13), indicating an association between plant canopy characteristics and forest carbon changes. Such findings were expected since increased photosynthetic capacity can influence the amount of carbon available to produce biomass during optimal environmental conditions (Collalti et al., 2020; Waring et al., 1998).

Forest carbon changes were sensitive to several water-related variables (Figures 3 and 4). However, the water-related conditions were less dominant than atmosphere conditions in explaining NABP (Figure 5a). In semi-arid regions, water availability was the dominant control of forest carbon changes (Figure 6a). Such findings suggested a coupling between the year-to-year variability of terrestrial carbon uptake and available water variations regionally (Ahlström et al., 2015; Humphrey et al., 2021; Jung et al., 2017). In very hot and dry regions and regions, atmosphere, water-related and vegetation conditions had limited controls on NABP variability (i.e. low SHAP values) (Figure $7 \mathrm{a}-\mathrm{c}$ ), suggesting that other environmental conditions that were not considered in our study might control forest carbon stocks' changes in these regions. Such assumption is somewhat corroborated by the modelling efficiency (i.e. Nash-Sutcliffe model efficiency coefficient) and RMSE estimates. In some regions, modelling efficiency is lower than 0.2 and RMSE higher than $1 \mathrm{MgC} \mathrm{ha}^{-1} \mathrm{year}^{-1}$ (Figure S8 and S10). The low predictive power of the models observed in such regions indicated an incomplete variable set and might have implications on the overall contribution of atmosphere, water related and vegetation in explaining NABP dynamics.

\section{3 | Relating forest carbon gain/loss and net $\mathrm{CO}_{2}$ uptake}

Typically, forest growth is associated with a carbon sink from the atmosphere to the land. Our study revealed that regions with longterm carbon gains are coupled with long-term carbon sink while regions with long-term carbon loss are coupled with a long-term carbon source (Figure 8a), demonstrating a covariation between net $\mathrm{CO}_{2}$ uptake and forest carbon changes at the regional scales. Only in the Central Asian region (i.e. CEAS), we observed a long-term forest net carbon loss (i.e. negative NABP), whereas there was a positive LAI trend (Figure S12) and a long-term carbon sink. This apparent 
paradox was surprising as NABP should reflect a similar trend as $\mathrm{LAI}$, and one should be interpreting NABP as an increase consistent with the trend in NBP. However, changes in management and/or landuse changes could decouple the relationship between NABP and the trend in LAI, and hence between NABP and primary productivity, and still create a carbon sink under reduction of forest carbon (e.g. transitions from mature forest to fast-growing forests).

Furthermore, we found that the magnitudes of NABP were substantially lower than the carbon sinks and sources' magnitudes (Figure 8a). This observation was possibly attributed to (i) belowground processes not being captured by the C-band AGB product (e.g. soil respiration and changes in below-ground carbon stocks), (ii) above-ground dynamics not accurately represented (e.g. underestimation of AGB in the high carbon stocks range) and (iii) the uncertainties in both the $\mathrm{C}$-band biomass and the atmospheric inversion products. The observed difference in magnitude could also be related to processes other than changes in AGB, such as fluctuations in environmental conditions that control photosynthetic and respiratory mechanisms, consequently a long-term mean of net $\mathrm{CO}_{2}$ fluxes. Finally, our results demonstrated that regions depicting high year to year NBP variations were generally regions with high NABP interannual variability (Figure $8 b$ ).

\section{5 | CONCLUSION}

Our results demonstrate how a novel record of global satellitederived estimates of AGB spanning almost three decades can provide relevant information on the controls of atmosphere, water-related and vegetation conditions on forest carbon changes. The most significant gains and losses occurred in forest ecosystems with carbon stocks ranging from 50 to $125 \mathrm{MgC} \mathrm{ha}^{-1}$, while older/mature forests showed minor carbon gain/loss sensitivities. Atmospheric conditions were the most dominant controls on forest carbon changes, while water-related conditions appeared important in semi-arid regions. Finally, we show a direct link between the long-term net forest carbon changes and the net $\mathrm{CO}_{2}$ fluxes and demonstrate that increasing carbon inputs through growth is generally coupled with a carbon sink at the ecosystem level. The radar observations used to generate the time record of 27 years of AGB estimates provide a unique insight in the 1990 decade; availability of observations throughout the next decades guarantee an extended timeline of observations. As a result, the $\mathrm{C}$-band global dataset of AGB shall provide among the most extended dataset of large-scale observations of vegetation carbon stocks. This will certainly substantially impact our understanding of forest carbon changes' sensitivities to fluctuations in environmental conditions, and therefore on the carbon cycle.

\section{ACKNOWLEDGEMENTS}

We thank C. Roedenbeck for sharing the Jena CarboScope inversion. We are grateful to R. Wang for sharing his Nitrogen and Phosphorus deposition datasets with us. We thank M. Migliavacca for his comments that improved the manuscript. We also thank the members of the Biogeochemical Integration Department at the Max Planck Institute for Biogeochemistry for providing feedback on the presented results. We acknowledge financial support by the European Space Agency through the BIOMASCAT project (Contract No. 40000125197/18/I-NB, EO Science for Society Permanently Open Call For Proposals EOEP-5 BLOCK, https://eo4society.esa.int/proje cts/biomascat/) and the European Union VERIFY project (776810) (https://cordis.europa.eu/project/id/776810). Open Access funding enabled and organized by Projekt DEAL.

\section{DATA AVAILABILITY STATEMENT}

The data that support the findings of this study are available from the corresponding author upon reasonable request.

\section{ORCID}

Simon Besnard (D) https://orcid.org/0000-0002-1137-103X

Richard Nair (D) https://orcid.org/0000-0002-6293-3610

\section{REFERENCES}

Achard, F., Beuchle, R., Mayaux, P., Stibig, H.-J., Bodart, C., Brink, A., Carboni, S., Desclée, B., Donnay, F., Eva, H. D., Lupi, A., Raši, R., Seliger, R., \& Simonetti, D. (2014). Determination of tropical deforestation rates and related carbon losses from 1990 to 2010. Global Change Biology, 20, 2540-2554. https://doi.org/10.1111/gcb.12605

Ahlström, A., Raupach, M. R., Schurgers, G., Smith, B., Arneth, A., Jung, M., Reichstein, M., Canadell, J. G., Friedlingstein, P., Jain, A. K., Kato, E., Poulter, B., Sitch, S., Stocker, B. D., Viovy, N., Wang, Y. P., Wiltshire, A., Zaehle, S., \& Zeng, N. (2015). The dominant role of semi-arid ecosystems in the trend and variability of the land $\mathrm{CO}_{2}$ sink. Science, 348, 895-899. https://doi.org/10.1126/scien ce.aaa1668

Allen, C. D., Breshears, D. D., \& McDowell, N. G. (2015). On underestimation of global vulnerability to tree mortality and forest die-off from hotter drought in the Anthropocene. Ecosphere, 6, art129. https:// doi.org/10.1890/ES15-00203.1

Baccini, A., Walker, W., Carvalho, L., Farina, M., Sulla-Menashe, D., \& Houghton, R. A. (2017). Tropical forests are a net carbon source based on aboveground measurements of gain and loss. Science, 358, 230-234. https://doi.org/10.1126/science.aam5962

Bar-On, Y. M., \& Milo, R. (2019). The global mass and average rate of rubisco. Proceedings of the National Academy of Sciences, 116, 47384743. https://doi.org/10.1073/pnas.1816654116

Bastos, A., Ciais, P., Chevallier, F., Rödenbeck, C., Ballantyne, A. P., Maignan, F., Yin, Y., Fernández-Martínez, M., Friedlingstein, P., Peñuelas, J., Piao, S. L., Sitch, S., Smith, W. K., Wang, X., Zhu, Z., Haverd, V., Kato, E., Jain, A. K., Lienert, S., ... Zhu, D. (2019). Contrasting effects of $\mathrm{CO}_{2}$ fertilization, land-use change and warming on seasonal amplitude of Northern Hemisphere $\mathrm{CO}_{2}$ exchange. Atmospheric Chemistry and Physics, 19, 12361-12375. https://doi. org/10.5194/acp-19-12361-2019

Beer, C., Reichstein, M., Tomelleri, E., Ciais, P., Jung, M., Carvalhais, N., Rödenbeck, C., Arain, M. A., Baldocchi, D., Bonan, G. B., Bondeau, A., Cescatti, A., Lasslop, G., Lindroth, A., Lomas, M., Luyssaert, S., Margolis, H., Oleson, K. W., Roupsard, O., ... Papale, D. (2010). Terrestrial gross carbon dioxide uptake: Global distribution and covariation with climate. Science, 329, 834-838. https://doi. org/10.1126/science.1184984

Bennett, A. C., McDowell, N. G., Allen, C. D., \& Anderson-Teixeira, K. J. (2015). Larger trees suffer most during drought in forests worldwide. Nature Plants, 1, 1-5. https://doi.org/10.1038/nplan ts.2015.139 
Besnard, S., Carvalhais, N., Arain, M. A., Black, A., de Bruin, S., Buchmann, N., Cescatti, A., Chen, J., Clevers, J. G. P. W., Desai, A. R., Gough, C. M., Havrankova, K., Herold, M., Hörtnagl, L., Jung, M., Knohl, A., Kruijt, B., Krupkova, L., Law, B. E., ... Reichstein, M. (2018). Quantifying the effect of forest age in annual net forest carbon balance. Environmental Research Letters, 13(12), 124018. https:// doi.org/10.1088/1748-9326/aaeaeb

Bonan, G. B. (2008). Forests and climate change: Forcings, feedbacks, and the climate benefits of forests. Science, 320, 1444-1449. https://doi.org/10.1126/science.1155121

Brienen, R. J. W., Phillips, O. L., Feldpausch, T. R., Gloor, E., Baker, T. R., Lloyd, J., Lopez-Gonzalez, G., Monteagudo-Mendoza, A., Malhi, Y. Lewis, S. L., Vásquez Martinez, R., Alexiades, M., Álvarez Dávila, E., Alvarez-Loayza, P., Andrade, A., Aragão, L. E. O. C., AraujoMurakami, A., Arets, E. J. M. M., Arroyo, L., ... Zagt, R. J. (2015). Long-term decline of the Amazon carbon sink. Nature, 519, 344348. https://doi.org/10.1038/nature14283

Cartus, O., Santoro, M., Wegmüller, U., \& Rommen, B. (2019). Benchmarking the retrieval of biomass in boreal forests using $\mathrm{P}$ band SAR backscatter with multi-temporal C- and L-band observations. Remote Sensing, 11, 1695. https://doi.org/10.3390/rs111 41695

Carvalhais, N., Reichstein, M., Ciais, P., Collatz, G. J., Mahecha, M. D., Montagnani, L., Papale, D., Rambal, S., \& Seixas, J. (2010). Identification of vegetation and soil carbon pools out of equilibrium in a process model via eddy covariance and biometric constraints. Global Change Biology, 16, 2813-2829. https://doi. org/10.1111/j.1365-2486.2010.02173.x

Collalti, A., Ibrom, A., Stockmarr, A., Cescatti, A., Alkama, R., FernándezMartínez, M., Matteucci, G., Sitch, S., Friedlingstein, P., Ciais, P., Goll, D. S., Nabel, J. E. M. S., Pongratz, J., Arneth, A., Haverd, V., \& Prentice, I. C. (2020). Forest production efficiency increases with growth temperature. Nature Communications, 11, 5322. https://doi. org/10.1038/s41467-020-19187-w

Collalti, A., \& Prentice, I. C. (2019). Is NPP proportional to GPP? Waring's hypothesis 20 years on. Tree Physiology, 39, 1473-1483. https://doi. org/10.1093/treephys/tpz034

Cowan, I. R., \& Farquhar, G. D. (1977). Stomatal function in relation to leaf metabolism and environment. Symposia of the Society for Experimental Biology, 31, 471-505.

de Vries, W., Du, E., \& Butterbach-Bahl, K. (2014). Short and long-term impacts of nitrogen deposition on carbon sequestration by forest ecosystems. Current Opinion in Environmental Sustainability, SI: System Dynamics and Sustainability, 9-10, 90-104. https://doi. org/10.1016/j.cosust.2014.09.001

de Vries, W., Leip, A., Reinds, G. J., Kros, J., Lesschen, J. P., Bouwman, A. F., Grizzetti, B., Bouraoui, F., Butterbach-Bahl, K., Bergamaschi, P., \& Winiwarter, W. (2011). Geographical variation in terrestrial nitrogen budgets across Europe. In A. Bleeker, B. Grizzetti, C. M. Howard, G. Billen, H. van Grinsven, J. W. Erisman, M. A. Sutton, \& P. Grennfelt (Eds.), The European nitrogen assessment: Sources, effects and policy perspectives (pp. 317-344). Cambridge University Press. https://doi.org/10.1017/CBO9780511976988.018

Engardt, M., Simpson, D., Schwikowski, M., \& Granat, L. (2017). Deposition of sulphur and nitrogen in Europe 1900-2050. Mode calculations and comparison to historical observations. Tellus B: Chemical and Physical Meteorology, 69(1), 1900-2050. https://doi. org/10.1080/16000889.2017.1328945

Etzold, S., Ferretti, M., Reinds, G. J., Solberg, S., Gessler, A., Waldner, P., Schaub, M., Simpson, D., Benham, S., Hansen, K., Ingerslev, M., Jonard, M., Karlsson, P. E., Lindroos, A.-J., Marchetto, A., Manninger M., Meesenburg, H., Merilä, P., Nöjd, P., ... de Vries, W. (2020). Nitrogen deposition is the most important environmental driver of growth of pure, even-aged and managed European forests. Forest Ecology and Management, 458, 117762. https://doi.org/10.1016/j. foreco.2019.117762
Fan, L., Wigneron, J.-P., Ciais, P., Chave, J., Brandt, M., Fensholt, R., Saatchi, S. S., Bastos, A., Al-Yaari, A., Hufkens, K., Qin, Y., Xiao, X., Chen, C., Myneni, R. B., Fernandez-Moran, R., Mialon, A., Rodriguez-Fernandez, N. J., Kerr, Y., Tian, F., \& Peñuelas, J. (2019). Satellite-observed pantropical carbon dynamics. Nature Plants, 1, https://doi.org/10.1038/s41477-019-0478-9

Fontes, C. G., Dawson, T. E., Jardine, K., McDowell, N., Gimenez, B. O., Anderegg, L., Negrón-Juárez, R., Higuchi, N., Fine, P. V. A., Araújo, A. C., \& Chambers, J. Q. (2018). Dry and hot: The hydraulic consequences of a climate change-type drought for Amazonian trees. Philosophical Transactions of the Royal Society B: Biological Sciences, 373, 20180209. https://doi.org/10.1098/rstb.2018.0209

Frank, D., Reichstein, M., Bahn, M., Thonicke, K., Frank, D., Mahecha, M. D., Smith, P., van der Velde, M., Vicca, S., Babst, F., Beer, C., Buchmann, N., Canadell, J. G., Ciais, P., Cramer, W., Ibrom, A., Miglietta, F., Poulter, B., Rammig, A., ... Zscheischler, J. (2015). Effects of climate extremes on the terrestrial carbon cycle: Concepts, processes and potential future impacts. Global Change Biology, 21, 2861-2880. https://doi.org/10.1111/gcb.12916

Friedlingstein, P., Meinshausen, M., Arora, V. K., Jones, C. D., Anav, A., Liddicoat, S. K., \& Knutti, R. (2013). Uncertainties in CMIP5 climate projections due to carbon cycle feedbacks. Journal of Climate, 27, 511-526. https://doi.org/10.1175/JCLI-D-12-00579.1

Gessler, A., Schaub, M., \& McDowell, N. G. (2017). The role of nutrients in drought-induced tree mortality and recovery. New Phytologist, 214, 513-520. https://doi.org/10.1111/nph.14340

Giglio, L., Randerson, J. T., \& van der Werf, G. R. (2013). Analysis of daily, monthly, and annual burned area using the fourth-generation global fire emissions database (GFED4). Journal of Geophysical Research: Biogeosciences, 118, 317-328. https://doi.org/10.1002/jgrg.20042

Green, J. K., Berry, J., Ciais, P., Zhang, Y., \& Gentine, P. (2020). Amazon rainforest photosynthesis increases in response to atmospheric dryness. Science Advances, 6, eabb7232. https://doi.org/10.1126/ sciadv.abb7232

Hansen, M. C., Potapov, P. V., Moore, R., Hancher, M., Turubanova, S. A., Tyukavina, A., Thau, D., Stehman, S. V., Goetz, S. J., Loveland, T. R., Kommareddy, A., Egorov, A., Chini, L., Justice, C. O., \& Townshend, J. R. G. (2013). High-resolution global maps of 21st-century forest cover change. Science, 342, 850-853. https://doi.org/10.1126/ science.1244693

Hauglustaine, D. A., Balkanski, Y., \& Schulz, M. (2014). A global model simulation of present and future nitrate aerosols and their direct radiative forcing of climate. Atmospheric Chemistry and Physics, 14 11031-11063. https://doi.org/10.5194/acp-14-11031-2014

Högberg, P. (2007). Nitrogen impacts on forest carbon. Nature, 447, 781 782. https://doi.org/10.1038/447781a

Hourdin, F., Musat, I., Bony, S., Braconnot, P., Codron, F., Dufresne, J.L., Fairhead, L., Filiberti, M.-A., Friedlingstein, P., Grandpeix, J.Y., Krinner, G., LeVan, P., Li, Z.-X., \& Lott, F. (2006). The LMDZ4 general circulation model: Climate performance and sensitivity to parametrized physics with emphasis on tropical convection. Climate Dynamics, 27, 787-813. https://doi.org/10.1007/s0038 2-006-0158-0

Hubau, W., Lewis, S. L., Phillips, O. L., Affum-Baffoe, K., Beeckman, H., Cuní-Sanchez, A., Daniels, A. K., Ewango, C. E. N., Fauset, S., Mukinzi, J. M., Sheil, D., Sonké, B., Sullivan, M. J. P., Sunderland, T. C. H., Taedoumg, H., Thomas, S. C., White, L. J. T., Abernethy, K. A., Adu-Bredu, S., ... Zemagho, L. (2020). Asynchronous carbon sink saturation in African and Amazonian tropical forests. Nature, 579, 80-87. https://doi.org/10.1038/s41586-020-2035-0

Humphrey, V., Berg, A., Ciais, P., Gentine, P., Jung, M., Reichstein, M., Seneviratne, S. I., \& Frankenberg, C. (2021). Soil moistureatmosphere feedback dominates land carbon uptake variability. Nature, 592, 65-69. https://doi.org/10.1038/s41586-021-03325-5

Ishibashi, M., Usuda, H., \& Terashima, I. (1996). The loss of ribulose1,5-bisphosphate carboxylase/oxygenase caused by 24-hour 
rain treatment fully explains the decrease in the photosynthetic rate in bean leaves. Plant Physiology, 111, 635-640. https://doi. org/10.1104/pp.111.2.635

Jung, M., Reichstein, M., Margolis, H. A., Cescatti, A., Richardson, A. D., Arain, M. A., Arneth, A., Bernhofer, C., Bonal, D., Chen, J., Gianelle, D., Gobron, N., Kiely, G., Kutsch, W., Lasslop, G., Law, B. E., Lindroth, A., Merbold, L., Montagnani, L., ... Williams, C. (2011). Global patterns of land-atmosphere fluxes of carbon dioxide, latent heat, and sensible heat derived from eddy covariance, satellite, and meteorological observations. Journal of Geophysical Research: Biogeosciences, 116, https://doi.org/10.1029/2010JG001566

Jung, M., Reichstein, M., Schwalm, C. R., Huntingford, C., Sitch, S., Ahlström, A., Arneth, A., Camps-Valls, G., Ciais, P., Friedlingstein, P., Gans, F., Ichii, K., Jain, A. K., Kato, E., Papale, D., Poulter, B., Raduly, B., Rödenbeck, C., Tramontana, G., ... Zeng, N. (2017). Compensatory water effects link yearly global land $\mathrm{CO}_{2}$ sink changes to temperature. Nature, 541, 516-520. https://doi.org/10.1038/nature20780

Jung, M., Schwalm, C., Migliavacca, M., Walther, S., Camps-Valls, G., Koirala, S., Anthoni, P., Besnard, S., Bodesheim, P., Carvalhais, N., Chevallier, F., Gans, F., Goll, D. S., Haverd, V., Köhler, P., Ichii, K., Jain, A. K., Liu, J., Lombardozzi, D., ... Reichstein, M. (2020). Scaling carbon fluxes from eddy covariance sites to globe: synthesis and evaluation of the FLUXCOM approach. Biogeosciences, 17, 13431365. https://doi.org/10.5194/bg-17-1343-2020

Konings, A. G., \& Gentine, P. (2017). Global variations in ecosystemscale isohydricity. Global Change Biology, 23, 891-905. https://doi. org/10.1111/gcb.13389

Le Quéré, C., Andrew, R. M., Friedlingstein, P., Sitch, S., Pongratz, J., Manning, A. C., Korsbakken, J. I., Peters, G. P., Canadell, J. G., Jackson, R. B., Boden, T. A., Tans, P. P., Andrews, O. D., Arora, V. K., Bakker, D. C. E., Barbero, L., Becker, M., Betts, R. A., Bopp, L., ... Zhu, D. (2018). Global carbon budget 2017. Earth System Science Data, 10, 405-448. https://doi.org/10.5194/essd-10-405-2018

Lin, Y.-S., Medlyn, B. E., Duursma, R. A., Prentice, I. C., Wang, H., Baig, S., Eamus, D., de Dios, V. R., Mitchell, P., Ellsworth, D. S., de Beeck, M. O., Wallin, G., Uddling, J., Tarvainen, L., Linderson, M.-L., Cernusak, L. A., Nippert, J. B., Ocheltree, T. W., Tissue, D. T., ... Wingate, L. (2015). Optimal stomatal behaviour around the world. Nature Climate Change, 5, 459-464. https://doi.org/10.1038/nclimate2550

Liu, K.-H., Fang, Y.-T., Yu, F.-M., Liu, Q., Li, F.-R., \& Peng, S.-L. (2010). Soil acidification in response to acid deposition in three subtropical forests of subtropical China. Pedosphere, 20, 399-408. https://doi. org/10.1016/S1002-0160(10)60029-X

Liu, S., Bond-Lamberty, B., Hicke, J. A., Vargas, R., Zhao, S., Chen, J., Edburg, S. L., Hu, Y., Liu, J., McGuire, A. D., Xiao, J., Keane, R., Yuan, W., Tang, J., Luo, Y., Potter, C., \& Oeding, J. (2011). Simulating the impacts of disturbances on forest carbon cycling in North America: Processes, data, models, and challenges. Journal of Geophysical Research: Biogeosciences, 116, https://doi.org/10.1029/2010JG001585

Lundberg, S. M., Erion, G. G., \& Lee, S. I. (2018). Consistent individualized feature attribution for tree ensembles. arXiv:1802.03888.

Lundberg, S. M., \& Lee, S. I. (2017). A unified approach to interpreting model predictions. arXiv. 1705.07874.

Luyssaert, S., Schulze, E.-D., Börner, A., Knohl, A., Hessenmöller, D., Law, B. E., Ciais, P., \& Grace, J. (2008). Old-growth forests as global carbon sinks. Nature, 455, 213-215. https://doi.org/10.1038/natur e07276

McDowell, N., Allen, C. D., Anderson-Teixeira, K., Brando, P., Brienen, R., Chambers, J., Christoffersen, B., Davies, S., Doughty, C., Duque, A., Espirito-Santo, F., Fisher, R., Fontes, C. G., Galbraith, D., Goodsman, D., Grossiord, C., Hartmann, H., Holm, J., Johnson, D. J., ... Xu, X. (2018). Drivers and mechanisms of tree mortality in moist tropical forests. New Phytologist, 219, 851-869. https://doi.org/10.1111/ nph.15027

McGroddy, M. E., Daufresne, T., \& Hedin, L. O. (2004). Scaling of C:n:p stoichiometry in forests worldwide: Implications of terrestrial redfield-type ratios. Ecology, 85, 2390-2401. https://doi. org/10.1890/03-0351

Miettinen, J., Shi, C., \& Liew, S. C. (2011). Deforestation rates in insular Southeast Asia between 2000 and 2010. Global Change Biology, 17, 2261-2270. https://doi.org/10.1111/j.1365-2486.2011.02398.x

Mitchard, E. T. A. (2018). The tropical forest carbon cycle and climate change. Nature, 559, 527-534. https://doi.org/10.1038/s4158 6-018-0300-2

Musavi, T., Migliavacca, M., Reichstein, M., Kattge, J., Wirth, C., Black, T. A., Janssens, I., Knohl, A., Loustau, D., Roupsard, O., Varlagin, A., Rambal, S., Cescatti, A., Gianelle, D., Kondo, H., Tamrakar, R., \& Mahecha, M. D. (2017). Stand age and species richness dampen interannual variation of ecosystem-level photosynthetic capacity. Nature Ecology and Evolution, 1, 0048. https://doi.org/10.1038/ s41559-016-0048

Nabuurs, G.-J., Lindner, M., Verkerk, P. J., Gunia, K., Deda, P., Michalak, R., \& Grassi, G. (2013). First signs of carbon sink saturation in European forest biomass. Nature Clim Change, 3, 792-796. https:// doi.org/10.1038/nclimate1853

Odum, E. P. (1969). The strategy of ecosystem development. Science, 164, 262-270. https://doi.org/10.1126/science.164.3877.262

Pan, Y., Birdsey, R. A., Fang, J., Houghton, R., Kauppi, P. E., Kurz, W. A., Phillips, O. L., Shvidenko, A., Lewis, S. L., Canadell, J. G., Ciais, P., Jackson, R. B., Pacala, S. W., McGuire, A. D., Piao, S., Rautiainen, A., Sitch, S., \& Hayes, D. (2011). A large and persistent carbon sink in the world's forests. Science, 333, 988-993. https://doi. org/10.1126/science.1201609

Phillips, O. L., Aragao, L. E. O. C., Lewis, S. L., Fisher, J. B., Lloyd, J., LopezGonzalez, G., Malhi, Y., Monteagudo, A., Peacock, J., Quesada, C. A., van der Heijden, G., Almeida, S., Amaral, I., Arroyo, L., Aymard, G., Baker, T. R., Banki, O., Blanc, L., Bonal, D., ... Torres-Lezama, A. (2009). Drought sensitivity of the Amazon Rainforest. Science, 323, 1344-1347. https://doi.org/10.1126/science.1164033

Piao, S., Zhang, X., Chen, A., Liu, Q., Lian, X., Wang, X., Peng, S., \& Wu, $X$. (2019). The impacts of climate extremes on the terrestrial carbon cycle: A review. Science China Earth Sciences, 62, 1551-1563. https://doi.org/10.1007/s11430-018-9363-5

Priestley, C. H. B., \& Taylor, R. J. (1972). On the assessment of surface heat flux and evaporation using large-scale parameters. Monthly Weather Review, 100, 81-92. https://doi.org/10.1175/15200493(1972)100<0081:OTAOSH>2.3.CO;2

Reichstein, M., Bahn, M., Ciais, P., Frank, D., Mahecha, M. D., Seneviratne, S. I., Zscheischler, J., Beer, C., Buchmann, N., Frank, D. C., Papale, D., Rammig, A., Smith, P., Thonicke, K., van der Velde, M., Vicca, S., Walz, A., \& Wattenbach, M. (2013). Climate extremes and the carbon cycle. Nature, 500, 287-295. https://doi.org/10.1038/nature12350

Reichstein, M., \& Carvalhais, N. (2019). Aspects of forest biomass in the earth system: Its role and major unknowns. Surveys in Geophysics, 40, 693-707. https://doi.org/10.1007/s10712-019-09551-x

Rödenbeck, C., Zaehle, S., Keeling, R., \& Heimann, M. (2018). How does the terrestrial carbon exchange respond to inter-annual climatic variations? A quantification based on atmospheric $\mathrm{CO}_{2}$ data. Biogeosciences, 15, 2481-2498. https://doi.org/10.5194/ bg-15-2481-2018

Saatchi, S., Asefi-Najafabady, S., Malhi, Y., Aragão, L. E. O. C., Anderson, L. O., Myneni, R. B., \& Nemani, R. (2013). Persistent effects of a severe drought on Amazonian forest canopy. Proceedings of the National Academy of Sciences, 110, 565-570. https://doi. org/10.1073/pnas.1204651110

Santoro, M., Cartus, O., Carvalhais, N., Besnard, S., \& Fan, N. (2020). Forest above-ground biomass estimates across three decades from spaceborne scatterometer observations, EGU General Assembly 2020, Online, 4-8 May 2020, EGU2020-19673. https://doi. org/10.5194/egusphere-egu2020-19673

Santoro, M., Cartus, O., Carvalhais, N., Rozendaal, D. M. A., Avitabile, V., Araza, A., de Bruin, S., Herold, M., Quegan, S., Rodríguez-Veiga, P., 
Balzter, H., Carreiras, J., Schepaschenko, D., Korets, M., Shimada, M., Itoh, T., Moreno Martínez, Á., Cavlovic, J., Cazzolla Gatti, R., ... Willcock, S. (2021). The global forest above-ground biomass pool for 2010 estimated from high-resolution satellite observations. Earth System Science Data, 13, 3927-3950. https://doi.org/10.5194/ essd-13-3927-2021

Santoro, M., Cartus, O., Fransson, J. E. S., \& Wegmüller, U. (2019). Complementarity of X-, C-, and L-band SAR backscatter observations to retrieve forest stem volume in Boreal Forest. Remote Sensing, 11, 1563. https://doi.org/10.3390/rs11131563

Schimel, D., Stephens, B. B., \& Fisher, J. B. (2015). Effect of increasing $\mathrm{CO}_{2}$ on the terrestrial carbon cycle. Proceedings of the National Academy of Sciences, 112, 436-441. https://doi.org/10.1073/ pnas. 1407302112

Schulte-Uebbing, L., \& de Vries, W. (2018). Global-scale impacts of nitrogen deposition on tree carbon sequestration in tropical, temperate, and boreal forests: A meta-analysis. Global Change Biology, 24, e416-e431. https://doi.org/10.1111/gcb.13862

Stibig, H.-J., Achard, F., Carboni, S., Raši, R., \& Miettinen, J. (2014). Change in tropical forest cover of Southeast Asia from 1990 to 2010. Biogeosciences, 11, 247-258. https://doi.org/10.5194/ bg-11-247-2014

Stovall, A. E. L., Shugart, H., \& Yang, X. (2019). Tree height explains mortality risk during an intense drought. Nature Communications, 10 , 4385. https://doi.org/10.1038/s41467-019-12380-6

Templer, P. H., Mack, M. C., lii, F. S. C., Christenson, L. M., Compton, J. E., Crook, H. D., Currie, W. S., Curtis, C. J., Dail, D. B., D'Antonio, C. M., Emmett, B. A., Epstein, H. E., Goodale, C. L., Gundersen, P., Hobbie, S. E., Holland, K., Hooper, D. U., Hungate, B. A., Lamontagne, S. ... Zak, D. R. (2012). Sinks for nitrogen inputs in terrestrial ecosystems: A meta-analysis of $15 \mathrm{~N}$ tracer field studies. Ecology, 93, 1816-1829. https://doi.org/10.1890/11-1146.1

Teuling, A. J., Seneviratne, S. I., Williams, C., \& Troch, P. A. (2006). Observed timescales of evapotranspiration response to soil moisture. Geophysical Research Letters, 33, https://doi. org/10.1029/2006GL028178

Thurner, M., Beer, C., Carvalhais, N., Forkel, M., Santoro, M., Tum, M., \& Schmullius, C. (2016). Large-scale variation in boreal and temperate forest carbon turnover rate related to climate. Geophysical Research Letters, 43(9), 4576-4585. https://doi.org/10.1002/2016G L068794

Tramontana, G., Jung, M., Schwalm, C. R., Ichii, K., Camps-Valls, G., Ráduly, B., Reichstein, M., Arain, M. A., Cescatti, A., Kiely, G., Merbold, L., Serrano-Ortiz, P., Sickert, S., Wolf, S., \& Papale, D. (2016). Predicting carbon dioxide and energy fluxes across global FLUXNET sites with regression algorithms. Biogeosciences, 13, 4291-4313. https://doi.org/10.5194/bg-13-4291-2016

Verbesselt, J., Umlauf, N., Hirota, M., Holmgren, M., Van Nes, E. H., Herold, M., Zeileis, A., \& Scheffer, M. (2016). Remotely sensed resilience of tropical forests. Nature Climate Change, 6, 1028-1031. https://doi.org/10.1038/nclimate3108

Vuorenmaa, J., Augustaitis, A., Beudert, B., Bochenek, W., Clarke, N., de Wit, H. A., Dirnböck, T., Frey, J., Hakola, H., Kleemola, S., Kobler, J., Krám, P., Lindroos, A.-J., Lundin, L., Löfgren, S., Marchetto, A.,
Pecka, T., Schulte-Bisping, H., Skotak, K., ... Forsius, M. (2018). Long-term changes (1990-2015) in the atmospheric deposition and runoff water chemistry of sulphate, inorganic nitrogen and acidity for forested catchments in Europe in relation to changes in emissions and hydrometeorological conditions. Science of the Total Environment, 625, 1129-1145. https://doi.org/10.1016/j.scito tenv.2017.12.245

Waldner, P., Marchetto, A., Thimonier, A., Schmitt, M., Rogora, M., Granke, O., Mues, V., Hansen, K., Pihl Karlsson, G., Žlindra, D., Clarke, N., Verstraeten, A., Lazdins, A., Schimming, C., lacoban, C., Lindroos, A.-J., Vanguelova, E., Benham, S., Meesenburg, H., ... Lorenz, M. (2014). Detection of temporal trends in atmospheric deposition of inorganic nitrogen and sulphate to forests in Europe. Atmospheric Environment, 95, 363-374. https://doi.org/10.1016/j. atmosenv.2014.06.054

Wang, R., Goll, D., Balkanski, Y., Hauglustaine, D., Boucher, O., Ciais, P., Janssens, I., Penuelas, J., Guenet, B., Sardans, J., Bopp, L., Vuichard, N., Zhou, F., Li, B., Piao, S., Peng, S., Huang, Y., \& Tao, S. (2017). Global forest carbon uptake due to nitrogen and phosphorus deposition from 1850 to 2100. Global Change Biology, 23, 4854-4872. https://doi.org/10.1111/gcb.13766

Waring, R. H., Landsberg, J. J., \& Williams, M. (1998). Net primary production of forests: A constant fraction of gross primary production? Tree Physiology, 18, 129-134. https://doi.org/10.1093/treep hys/18.2.129

Wigneron, J.-P., Fan, L., Ciais, P., Bastos, A., Brandt, M., Chave, J., Saatchi, S., Baccini, A., \& Fensholt, R. (2020). Tropical forests did not recover from the strong 2015-2016 El Niño event. Science Advances, 6, eaay4603. https://doi.org/10.1126/sciadv.aay4603

Xiao, Z., Liang, S., Wang, J., Xiang, Y., Zhao, X., \& Song, J. (2016). Longtime-series global land surface satellite leaf area index product derived from MODIS and AVHRR surface reflectance. IEEE Transactions on Geoscience and Remote Sensing, 54, 5301-5318. https://doi.org/10.1109/TGRS.2016.2560522

Zhao, B., Zhuang, Q., Shurpali, N., Köster, K., Berninger, F., \& Pumpanen, J. (2021). North American boreal forests are a large carbon source due to wildfires from 1986 to 2016. Scientific Reports, 11, 7723. https://doi.org/10.1038/s41598-021-87343-3

\section{SUPPORTING INFORMATION}

Additional supporting information may be found in the online version of the article at the publisher's website.

How to cite this article: Besnard, S., Santoro, M., Cartus, O., Fan, N., Linscheid, N., Nair, R., Weber, U., Koirala, S., \& Carvalhais, N. (2021). Global sensitivities of forest carbon changes to environmental conditions. Global Change Biology, 00, 1-17. https://doi.org/10.1111/gcb.15877 